Quebec Cooperative Study of Friedreich's Ataxia

\title{
Friedreich's Disease 1982: Etiologic Hypotheses A personal analysis
}

\author{
ANDRÉ BARBEAU
}

SUMMARY: The author reviews the arguments for and against the four etiologic hypotheses in Friedreich's disease that have been proposed since 1974: the "pyruvate hypothesis", the "lipidmembrane hypothesis", the "energy-defect hypothesis" and finally the "taurine hypothesis". While none of these hypotheses are mutually exclusive, the author shows that all of these mechanisms play some role in the pathophysiology of the

RÉSUMÉ: Dans cet article l'auteur passe en revue les arguments en faveur et contre chacune de 4 hypothèses étiologiques proposées depuis 1974 pour expliquer la maladie de Friedreich: l'hypothèse "Pyruvate"; l'hypothèse "lipides-membranes"; l'hypothèse "défaut énergétique" et l'hypothèse "taurine". Aucune de ces hypothèses n'est mutuellement exclusive et il est probable que tous les mécanismes proposés jouent un rôle dans la genèse des symptômes, mais seule l'hypothèse "taurine" symptoms, but that only the "taurine hypothesis" appears to be compatible with all the known facts and the biochemical abnormalities reported. The author proposes that a taurine retention defect (possibly due to a block in the high affinitylow capacity transport of taurine - The TH System) is a primary event in Friedreich's disease. Whether it is the primary genetic event still has to be determined.

semble répondre aux critères cliniques et aux données biochimiques de la maladie telle que nous la connaisons. L'auteur propose enfin qu'un défaut de rétention de la taurine (peut-être consécutif à un bloc dans le transport à haute affinité et basse capacité de la taurine - le système TH) constitue un évènement primaire dans la maladie de Friedreich. Seules d'autres expériences nous dirons s'il s'agit vraiment du seul évènement génétique primaire.
From the Department of Neurobiology, Clinical Research Institute of Montreal.

Reprint requests for the complete supplement on Friedreich's Ataxia (Phase Three, Part Two) to: Prof André Barbeau, Clinical Research Institute of Montreal, 110 Pine Avenue West, Montreal, Quebec, Canada, H2W IR 7 .

\section{INTRODUCTION}

The previous 4 issues of the Canadian Journal of Neurological Sciences devoted to Friedreich's Ataxia have uncovered a wealth of information and new biochemical data that may have tended to confuse the issue, rather than clarify it (Barbeau, $1976,1978,1979,1980)$. It is now urgent to attempt searching for some order in all these publications, because the pace of research on the hereditary spino-cerebellar degenerations has accelerated considerably. As the investigations unfolded, etiological hypotheses came to the fore to explain the findings and they received their ephemeral moment of glory in the scientific and lay press, only to be displaced by the newest explanations. As is always the case, some of the data presented to support each theory has withstood the test of time, and of competing laboratories, but other "facts" have had to be relegated to the "circular file". In order to gain acceptance as a valid etiological theory, any hypothesis must explain all the known (and confirmed) biochemical anomalies as well as being compatible with genetic and clinical data accumulated for that illness and with the pathophysiology of symptoms (Barbeau, 1980). Since 1974, four hypotheses on the etiology of Friedreich's Ataxia have been proposed. For simplicity sake I will characterize them by their principal individual focus: the "pyruvate hypothesis", the "lipid-membrane hypothesis", the "energy defect hypothesis", and more recently the "taurine hypothesis". None however are mutually exclusive. In this paper I intend to critically review each of these hypotheses, examining the arguments 
for and against them and analysing how they attempt to explain all the biochemical data. Before $I$ do so however, it will be better to first define clearly what has to be explained, clinically and biochemically.

\section{FACTS TO BE ACCOUNTED FOR IN FRIEDREICH'S DISEASE}

\section{(a) Clinico-pathological facts}

Most authors have commented on the wide variability of symptoms, even within families (see Tyrer, 1975; Greenfield, 1954), a fact which has rendered classification of the spinocerebellar degenerations almost impossible (see Barbeau, 1982, this issue). It is now well recognized that Friedreich's Ataxia is not a disease limited to the central nervous system, as evidenced by the sensory polyneuropathy, the cardiomyopathy and by the metabolic changes of diabetes (Tyrer, 1975; Barbeau, 1976). Many new biochemical alterations have now been added to this complex picture and all must be explained in the framework of a working hypothesis. It is, however, extremely difficult to sort out which signs and symptoms have a chance to be primary (ie directly related to the causal factor, if not that factor itself) and which are secondary (a consequence of one or more of the "primary" events). This search should be made easier by the study of subjects who have the genetic defect but have not yet developed the symptoms. Unfortunately, since no exact marker of Friedreich's Ataxia has yet been discovered, we must rely entirely on chance. In the course of the first 6 years of the Quebec Cooperative Study (the QCSFA) I had the occasion to examine a number of clinically unaffected siblings of my patients. To this day only 4 have developed signs of ataxia (Table l). It is interesting to compare their neurological examination at that time ( 2 to 5 years before the onset of ataxia) with the list of symptoms now accepted as criteria for a "typical case" of Friedreich's Ataxia (Geoffroy et al, 1976). It can be seen that none of the future patients had Ataxia (by definition), muscle weakness, extensor plantar responses, nystagmus or scoliosis. Most had a

Table 1

PRE-ATAXIA SYMPTOMS IN FOUR PATIENTS WITH TYPICAL FRIEDREICH'S DISEASE

\section{ITEM}

Sex

Age at first examination

Age of onset of ataxia

Positive cases in siblings

SYMPTOMS

a) Ataxia of gait

b) knee jerk areflexia

c) dysarthria

d) decreased vibration sense

e) muscle weakness

f) extensor olantar

g) pes cavus

h) scoliosis

i) nystagmus

\section{SENSORY NERVE CONDUCTION \\ (sural nerve) \\ $\mathrm{m} / \mathrm{sec}$ ( $\mathrm{N}>35$ ) \\ CARDI.C SIGNS (ECG, VCG, \\ Echocardiogram)}

DIABETES decreased vibration sense and signs of a cardiomyopathy while all 4 subjects had knee jerk areflexia and markedly decreased or absent nerve conduction in the sural nerve. The last 3 signs thus have a much higher probability of being closer to the primary defect than any of the others. Any theory of etiology in that disease must thus be able to adequately explain the pathophysiology of these 3 "primary" signs: cardiomyopathy, areflexia and decreased deep sensory conduction (particularly position and vibration sense). Even the symptom of Ataxia, which brings patients to our attention, is a secondary event, a consequence of the above problems. An analysis of the pathology and of the physiology of Friedreich's Ataxia (see Oppenheimer,
1979; Côté et al, 1976; Peyronnard et al, 1976) leads to the conclusion that underlying these 3 "primary" symptoms are two main pathologies: a hypertrophic cardiomyopathy and a "dying-back" neuropathy in nerve fibers originating from the large bipolar cells of the dorsal root ganglia and reaching to the cerebellum through the posterior columns in one direction, or to the tip of all 4 limbs (particularly the lower limbs) in the other direction. Again, any theory on the etiology of Friedreich's Ataxia should adequately explain these two pathological loci (Table 2). Logic would dictate that from now on, we adopt the French and German nomenclature and talk about Friedreich's Disease rather than Friedreich's Ataxia, since ataxia is not 


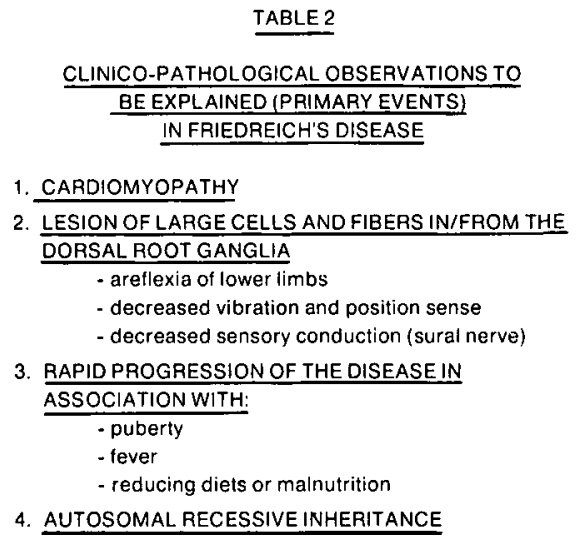

even a primary event in that disease; unfortunately habits are hard to break!

\section{(b) Metabolic observations}

The detailed biochemical studies on Friedreich's Disease undertaken since 1975 (for review see Lubozynski and Roelofs, 1975; Barbeau 1976, 1978, 1979,1980 and the present issue) have revealed a great number of metabolic and biochemical alterations from the thousands of biochemical determinations made. Most results, of course, were within the normal range (the knowledge of this is equally useful in elaborating coherent views), but 44 findings were abnormal (ie significantly different from those in adequate normal control groups) in Friedreich's Disease. Of these, 24 have now been confirmed in at least one other laboratory from the one contributing the initial report (Table 3). Many more recent findings have yet to be tested elsewhere.

Not every one of the biochemical alterations were found in every patient tested (in fact very few did), but no more than 15 of the 44 significant changes were observed in only "some" of the patients with the "typical" disease. If the latter can be classified immediately as "secondary" events, we are still faced with the burden of proof for some 29 statistically significant events. Which of these is/are "primary"? This is what we will now attempt to examine.

Whatever hypothesis (or combination thereof) is retained after this analysis, will also have to explain certain peculiarities of the evolution of Friedreich's disease. Personal observation of some 300 cases over the last 6 years has indeed shown that more rapid progression of the illness occurs in association with three types of events: puberty (rapid growth period), fever (of whatever origin) and reducing diets (particularly low fat diets or malnutrition due to other medical or economic factors). (Table 2). As stated previously, four main hypotheses have been proposed to explain the etiology of Friedreich's disease:

\section{(A) THE "PYRUVATE HYPOTHESIS"}

The hypothesis can be stated thus: "The primary event in Friedreich's dis- ease is related to a deficiency in the Pyruvate dehydrogenase complex (PDHc) or in one of its components or co-factors". The initial observation was that of Thorén (1962) who documented a higher incidence of diabetes in Friedreich's disease. In 1974 Kark and collaborators reported defective pyruvate oxidation in muscle in a variety of ataxic syndromes and in 1975 Barbeau demonstrated an abnormal handling of pyruvate after a glucose load in the blood of patients with the typical disease. The initial observations have since been confirmed in most laboratories (for review see Barbeau, 1980; also more recently: Constantopoulos, 1980; Livingstone et al, 1980; Evans, 1981; Purkiss et al, 1981) but further studies from the

METABOLIC ANOMALIES TO BE EXPLAINED IN FRIEDREICH'S DISEASE

\begin{tabular}{|c|c|c|c|c|c|c|}
\hline & & ANOMALIES & Direction & Prese & typical & atients \\
\hline A. & & & & All & Most & Some \\
\hline & 1. & Serum & & & & \\
\hline & & a. triglycerides & $\mathrm{H}^{*}$ & & + & \\
\hline & & b. unconjugated bilirubin & $\mathrm{H}^{*}$ & & & + \\
\hline & & c. lipoamide dehydrogenase (LAD) & $\mathrm{L}^{*}$ & & + & \\
\hline & & d. lactate dehydrogenase (LDH) & $H^{*}$ & & + & \\
\hline & & e. vitamin $\mathrm{E}$ & $\mathrm{L}$ & & & + \\
\hline & 2. & Blood & & & & \\
\hline & & a. $\mathrm{HDL} / \mathrm{PC}(18: 2)$ & $L^{*}$ & & + & \\
\hline & & b. HDL/CE $(18: 2)$ & $\mathrm{L}^{*}$ & & + & \\
\hline & & c. glucose (diabetes) & $H^{*}$ & & & + \\
\hline & & d. pyruvate (after glucose load) & $\mathrm{H}^{*}$ & & & + \\
\hline & 3. & Plasma & & & & \\
\hline & & a. aspartic acid & L & & + & \\
\hline & & b. glycine & $\mathrm{L}$ & & + & \\
\hline & & c. Phenylalanine & $L$ & & & + \\
\hline & & d. $\alpha$-keto glutarate & $\mathrm{H}$ & & + & \\
\hline & & e. $\alpha$-KIVAL & $\mathrm{H}$ & & + & \\
\hline & & f. $\alpha$-KICAP & $H$ & & & + \\
\hline & & g. LCAT & $\mathrm{L}^{*}$ & & + & \\
\hline & & h. hepatic lipase & L & & & + \\
\hline & & i. lipoprotein lipase & $\mathrm{L}$ & & & + \\
\hline & & j. free catecholamines & $\mathrm{H}^{*}$ & & + & \\
\hline & & k. $C E(18: 2)$ & $L$ & & + & \\
\hline & 4. & W.B.C. & & & & \\
\hline & & $\overline{\text { a. } \mathrm{PDH}}$ & $\mathrm{L}^{*}$ & & & + \\
\hline & & b. $\alpha-\mathrm{KGDH}$ & $L^{*}$ & & & + \\
\hline & & c. $\mathrm{GDH}$ & $\mathrm{L}^{*}$ & & + & \\
\hline & & d. VDH & $\mathrm{L}$ & & + & \\
\hline & 5. & Platelets & & & & \\
\hline & & a. $\mathrm{PDH}$ & $L^{*}$ & & & + \\
\hline & 6. & R.B.C. & & & & \\
\hline & & $\overline{\text { a. } 18: 2} \mathrm{PC}$ content & $L^{*}$ & & + & \\
\hline
\end{tabular}


groups of Kark and the QCSFA have diverged somewhat, particularly in interpretation. Pyruvate oxidation is an extremely complex biochemical phenomenon which has been shown by Reed and his co-workers (Reed, 1974) to comprise a successive cascade of at least three enzymatic steps under the regulatory control of two more enzymes. At each of these steps cofactors also play an important role. As illustrated in Fig. 1, the first component of the complex is pyruvate decarboxylase $\left(E_{1}\right)$, a thiamine pyrophosphate (TPP) dependent enzyme. The second step $\left(E_{2}\right)$ is the enzyme lipoyl reductase transacetylase. The co-factors at this level are coenzyme A (formed partially from pantothenic acid) and lipoic acid. The last step $\left(E_{3}\right)$ is dehydrolipoyl dehydrogenase, also called lipoamide dehydrogenase (LAD), employing flavinadenine-dinucleotide (FAD) as cofactor and under the control of the nicotinamide - adenine - dinucleotide (NAD-NADH) reaction. The function of $L A D$ is to regenerate oxidized lipoic acid. Finally, this tri-enzyme complex can be found in the active or inactive states, transformation between the two states being dependent upon a kinase (to phosphorylated, inactive state) or a phosphatase (to dephosphorylated, active state) and the divalent ions calcium and magnesium. In the presence of calcium, the phosphatase binds to the transacetylase moiety, favoring dephosphorylation.

The studies concerning this enzyme complex have given contradictory results. Kark and his group (Kark and Rodriguez-Budelli, 1979a, 1979b; Kark et al, 1980; Rodriguez-Budelli and Kark, 1978) have pinpointed the defect, in some of their patients, to the LAD component. They have even claimed that kinetic abnormalities in this enzyme were the probable basic defect in these patients, demonstrating a genetic pattern to the kinetic changes and even predicting the development of ataxia in one case. As reviewed by me in 1980 (Barbeau, 1980) most other authors have not been able to confirm these changes, particularly in fibroblasts, except a decrease in PDHc in muscle and platelets in some patients with the typical picture of Friedreich's disease, and a significant decrease in
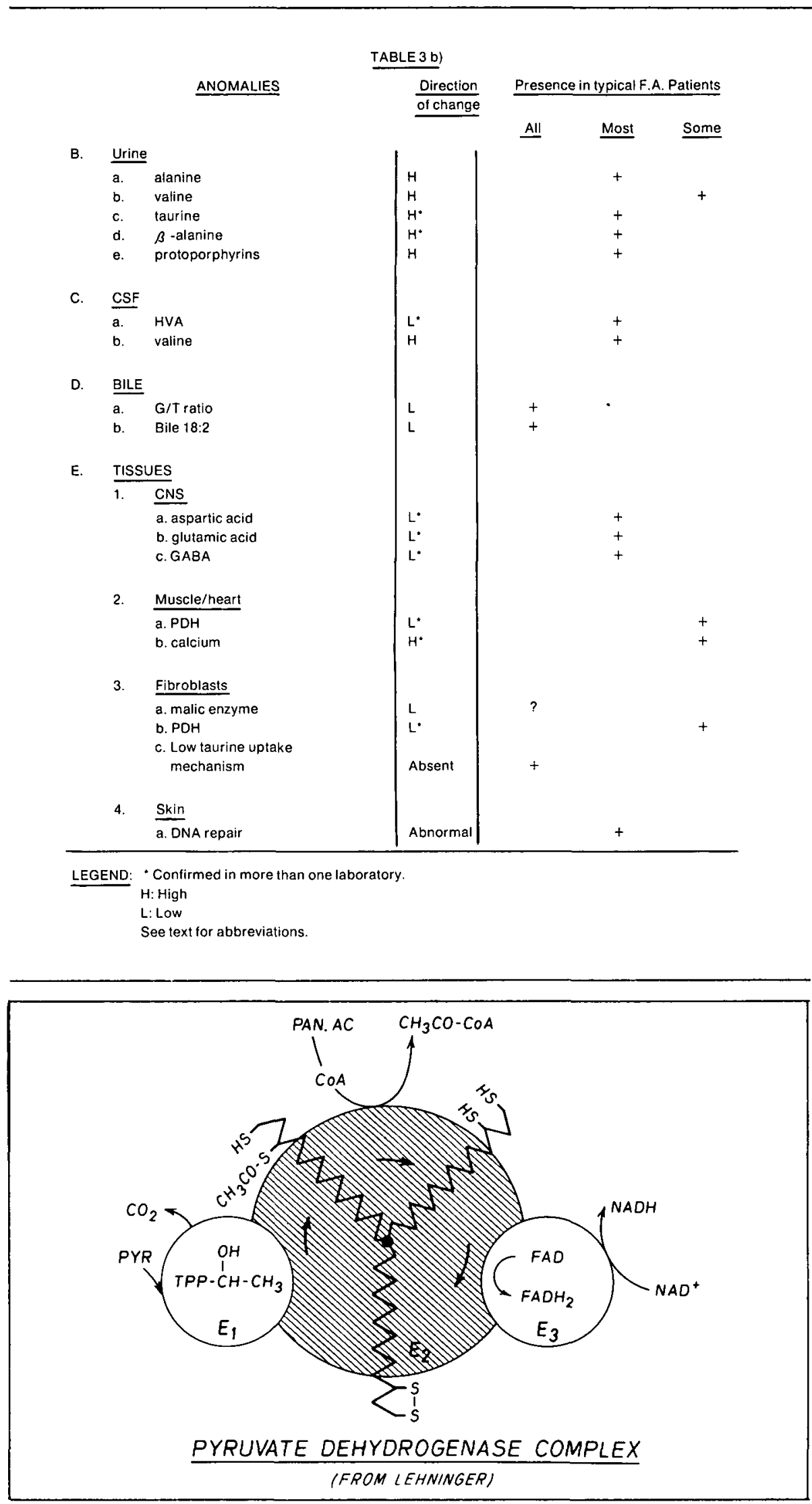

Figure 1 - The pyruvate dehydrogenase complex as illustrated by Lehninger. 
serum LAD, also in some patients, a defect which is reversible after supplementation with linoleic acid. Individual components of the complex have also been studied (for complete references, see Barbeau, 1980): the intrinsic activity of $E_{1}$ and $E_{2}$ have been shown to be normal, and there is no defect in the transformation from the inactive to the active stages. $\mathrm{LAD}\left(\mathrm{E}_{3}\right)$ activity is confirmed to be decreased in the serum of some patients, but this is a substrate specific finding. The cofactors thiamine and riboflavin have been found normal and supplementation in patients with these two vitamins has not changed the clinical picture. In more recent studies, to test for a possible deficiency of riboflavin (vitamin $B_{2}$ ), we chose the measurement of the enzyme glutathione reductase (EC 1.6.4.2; $\mathrm{NAD}(\mathrm{P}) \mathrm{H}$ : glutathione oxidoreductase) before and after activation by the co-factor flavin-adenine dinucleotide (FAD), according to the procedure described by Bayoumi and Rosalki (1976). In 8 control subjects we found an activation of $23.8 \pm$ $2.7 \%$, while in 8 Friedreich's ataxia patients the activation was $34.5 \pm$ $4.4 \%$. This difference, while indicating a very slight deficiency in riboflavin in patients versus controls, is still within the normal range (up to $76 \%$ ) and is therefore not physiologically significant. In follow-up studies, the same patients were treated for 6 months with oral supplements of riboflavin without any change in their clinical or biochemical status.

However the co-factors of the $E_{2}$ (transacetylase) component have not been properly studied. Lipoic acid and coenzyme A were found to be hard to measure and we have not yet resolved the technical difficulties. However, we were able to indirectly estimate CoA formation in Friedreich's disease. As seen in Fig. 2, pantothenic acid is an important component of coenzyme A. Urinary pantothenic acid was measured and found to be significantly elevated in Friedreich's disease, possibly indicating that the incorporation into coenzyme A may be defective, or that CoA cannot be properly utilized because of a defect in or a lack of lipoic acid. These points must still be confirmed.

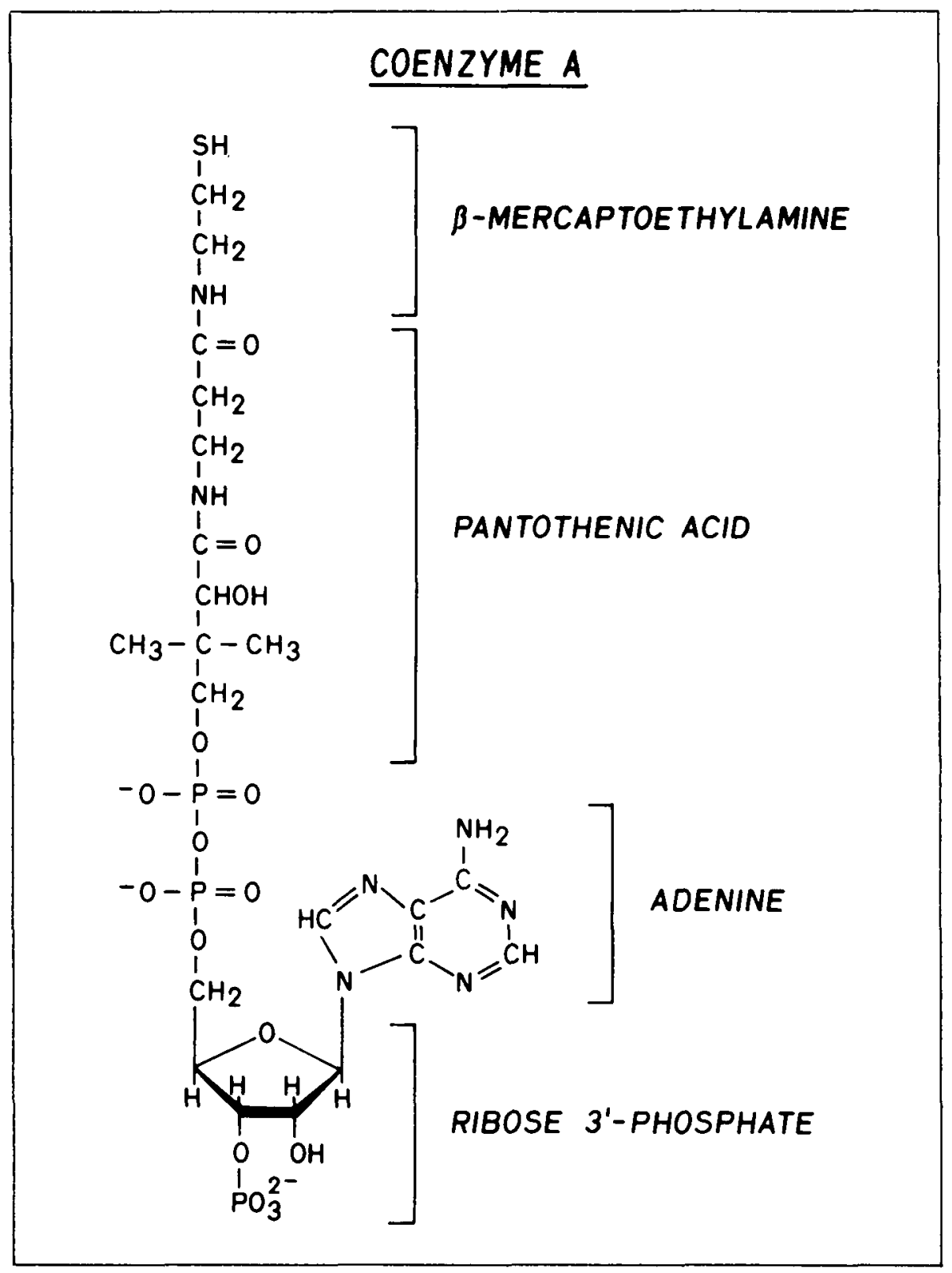

Figure 2 - To indirectly test whether a deficiency in pantothenic acid could be responsible for the slow-down in $\mathrm{PDH}_{\mathrm{c}}$ activiy, we measured the urinary excretion of panthothenic acid with the method of Baker and Frank (1965). The results indicate values of $2.19 \pm 0.41 \mathrm{mg} / \mathrm{g}$ creatinine for 11 normal controls, $2.35 \pm 0.49$ in 9 neurological controls and $3.96 \pm 0.71 \mathrm{mg} / \mathrm{g}$ creatinine in 10 patients with Friedreich's disease. This latter group was significantly different $(p<0.05)$ from the controls. (Charbonneau, M. and Barbeau, A., unpublished results).

The LAD component of the PDHc is also present in other multienzyme complexes, so are the co-factors of the $\mathrm{E}_{2}$ enzyme. The complexes usually differ by their decarboxylase component $\left(E_{1}\right)$. It is thus of interest that the activities of $\alpha$-keto glutarate dehydrogenase (Kark et al, 1974) and valine dehydrogenase (Barbeau et al, 1982, this issue) similar multienzyme complexes, were also found to be decreased by $20-40 \%$ in some, but not in all, patients.

What must we conclude, from our present knowledge, on the chance for a deficiency in pyruvate dehydrogenase (and associated complexes) of being a "primary event" in Friedreich's disease?

\section{A) Arguments against}

1. Not universal: Because the defect 
in pyruvate oxidation and the serum LAD deficiency or postulated kinetic defect are only present in some, but not in all patients, these findings cannot be considered "primary events", unless we postulate two biochemically different disorders.

2. Not of sufficient amplitude: Even when present the deficiency rarely surpasses $40 \%$, a finding incompatible with a primary mutant gene product in a recessive disorder. It is not, however, inconsistent with being the causal factor for some of the symptoms.

3. Not specific. The deficiency in pyruvate oxidation is not specific to Friedreich's disease, being equally found in other ataxic entities (Charlevoix-Saguenay syndrome;
Charcot-Marie-Tooth disease; various poly-neuropathies).

\section{Site of defect not identified:} Moreover the defect, if present, cannot yet be localized. On this point two theories clash strongly. Kark and his associates localize the defect to the LAD enzyme component itself and make it the primary mutation. Barbeau and his coworkers feel that the LAD deficiency is a substrate related event secondary to a defective regulation at the transacetylase step. They postulate an abnormal supply or binding capacity of the lipoic acid co-factor, a defect possibly reflected in the non-utilization of coenzyme A and pantothenic acid.

\section{B) Arguments for}

1. Genetic pattern: The fact that the disturbance appears to follow a genetic pattern in some families is not in itself sufficient evidence for a primary defect. A secondary event, linked by direct consequence to the basic defect, again in some patients, would tend to follow the same hereditary pattern. The lack of confirmation concerning the transmission of the PDH defect in fibroblasts would have to be considered an argument against the "primary" hypothesis.

2. Compatible with physiopathology: A deficiency in pyruvate, $\alpha$ ketoglutarate and $\alpha$-keto isovalerate utilization would however be compatible with the observed energy production defect

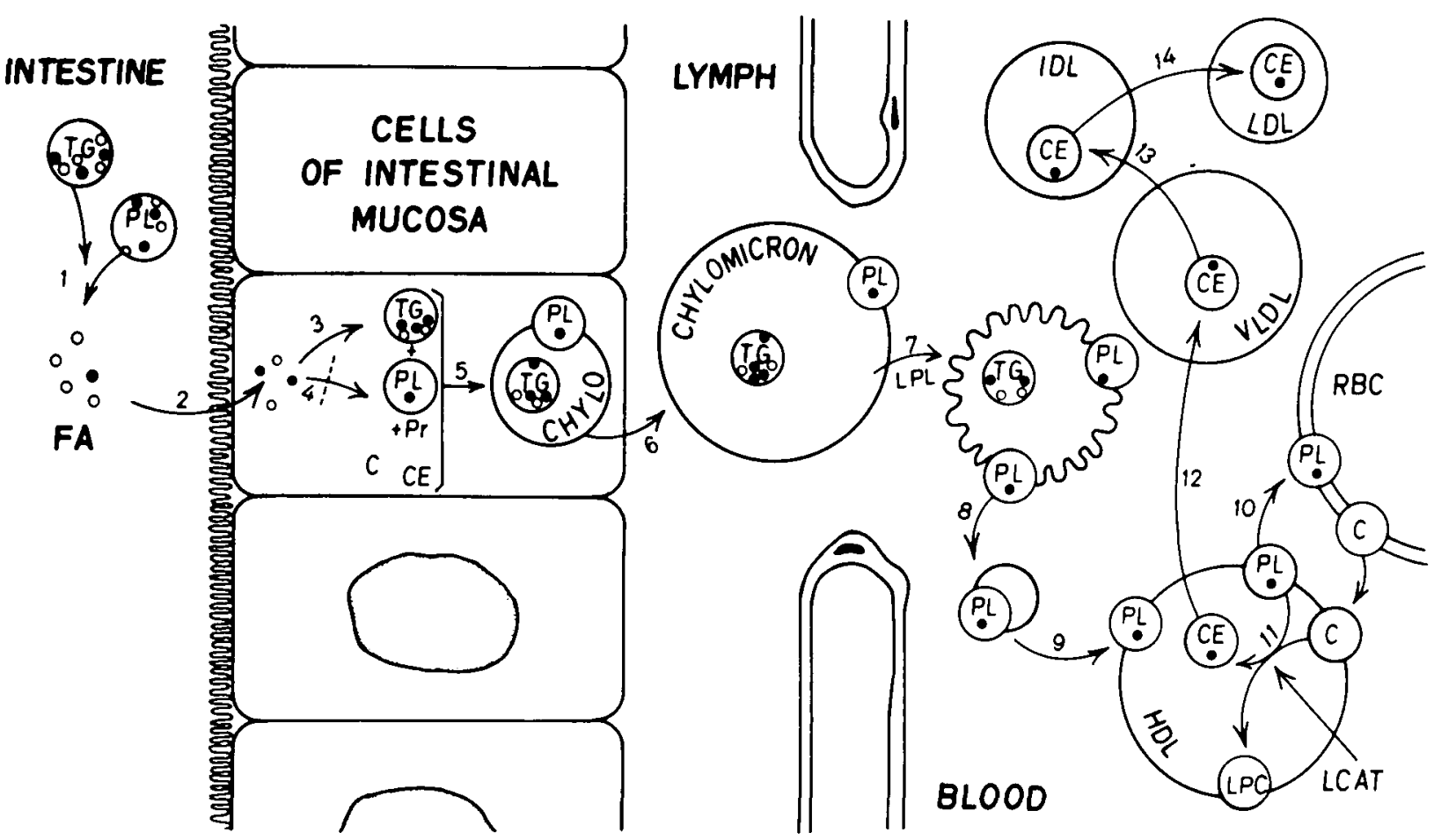

Figure 3 - Working hypothesis and tentative explanation for the relative deficiency in linoleic acid in Friedreich's disease. Dietary triglycerides (TG) and phospholipids (PL) are hydrolyzed in the intestine (1) to release fatty acids poor in linoleic acid (18:2) represented by black dots. These fatty acids are absorbed (2), incorporated normally into triglycerides (3) but not sufficiently into the phospholipids (4) of the Friedreich patient. The association of TG, PL, cholesterol (C) and cholesteryl esters (CE) to apolipoproteins synthesized in the intestinal mucosa result in the formation of chylomicrons (5) which are relatively deficient in 18:2. These fat globules are transferred into the lymph (6) to reach the blood. Lipoprotein lipase gradually reduces their TG content (7) and their surface rich in protein, phospholipids and cholesterol becomes in excess relative to the volume of the particle, redundant and irregular. Pieces of this lamellar structure detach (8) to form vesicles which are taken up by HDL (9). Thus the chylomicron surface transfers to HDL phospholipids that are deficient in 18:2. These PL will be incorporated as such in the red blood membrane (10) and serve as substrate for lecithin cholesterol acyl transferase (LCAT) (11) to form cholesteryl esters, the composition of which will be relatively deficient in 18:2. These CE are then transferred to VLDL (12) who will follow their catabolic cascade to intermediate density lipoproteins (IDL) (13) and finally to LDL (14). The CE of LDL will thus also be deficient in 18:2. Figure and legend from Huang et al, (1980). 
found in this disease (see infra) and its consequences (neuropathy, cardiomyopathy, scoliosis etc.)

\section{C) On Balance}

On balance very little favours a "primary event" at the level of the pyruvate dehydrogenase complex in Friedreich's disease. There is no doubt, however, that such a defect does exist, secondarily, in some patients and, in those patients, contributes to the deficit in cell energy production. To evaluate the presence of this defect, the measurement of VDH is recommended because it is more stable and less influenced by previous intake of glucose, and because it incorporates the same $\mathrm{E}_{3}$ component and the same co-factors of the transacetylase moiety.

\section{(B) THE LIPID-MEMBRANE} HYPOTHESIS

The hypothesis can be stated thus: "The primary event in Friedreich's disease is related to a defect in the incorporation of linoleic acid into phospholipids and consequently to a deficiency in linoleic acid in membrane components, particularly the mitochondrial membrane". The initial ob- servations were the knowledge that lipids and their transport lipoproteins were involved in two diseases clinically closely related to Friedreich's disease: Refsum's Phytanic Acid Storage disease (Refsum, 1946) and a-betalipoproteinemia, or Bassen-Kornzweig disease (Bassen and Kornzweig, 1950). The finding of low normal cholesterol levels in most patients, coupled to significantly higher but still normal mean triglyceride levels (Butterworth et al, 1976) were also a stimulus for this work. Following upon these leads, Huang et al, (1978) studied the lipoprotein composition of the patients and reported major differences from control in the high density lipoprotein (HDL) fractions. Their total amount was reduced and their composition was abnormal: the relative proportion of cholesterol and triglycerides was increased, while the relative protein content was greatly reduced.

In further studies, Davignon et al, (1979) showed that the protein fraction of $\mathrm{HDL}$ was normal. Apoproteins $\mathrm{A}_{1}$ and $A_{2}$ were within normal limits and so was the gel electrophoresis pattern. In unpublished preliminary studies (Davignon, 1982) the apoproteins E were also normal. It is thus in the other fractions that it was necessary to search for the HDL anomaly. It was shown that the fatty acid profile of the cholesterylester (CE) fraction was deficient in 18:2 in both total plasma and HDL, with a compensatory increase in saturated acids. The HDL phospholipid (PL) fraction also showed a reduction in the proportion of 18:2 with a concomitant increase in stearic (18:0) and oleic acid (18:1). This pattern of low CE 18:2 was also present in low density lipoproteins (LDL). From these data Davignon et al, (1978) proposed the existence of a metabolic defect in the incorporation of $18: 2$ into chylomicron phospholipids within the intestinal mucosa (Fig. 3). This was supported by low levels of Lecithin: cholesterol acyltransferase (LCAT) and decreased phosphatidyl choline 18:2 in red blood cell membranes (Huang et al, 1980), and later by low levels of lipoprotein lipase and hepatic lipase (Blache et al, 1982, this issue). Some of these findings were confirmed by Filla et al, (1980) in Italy and Yao and Dick (1978) in the USA, but not by Walker et al, (1980) in England. There is no clear reason yet found to explain these differences in results.

\begin{tabular}{|c|c|c|c|c|c|}
\hline \multicolumn{6}{|c|}{ PLASMA CHOLESTEROL / TRIGLYCERIDE RATIO } \\
\hline \multicolumn{6}{|c|}{ IN ATAXIC SYNDROMES } \\
\hline & CONTROL SUBJECTS & F.S.P. & FRTEDREICH & C.S.S. & $\underline{R L}=C M T$ \\
\hline$n$ & 35 & 11 & 35 & 11 & 17 \\
\hline $\begin{array}{c}\text { Choles terol } \\
\text { (mg\% SEM) }\end{array}$ & $163.1 \pm 5.7$ & $195.2 \pm 14.9 *$ & $167.0 \pm 5.1$ & $178.3 \pm 14.8$ & $202.6 \pm 10.0 * \star$ \\
\hline $\begin{array}{l}\text { Triglycerides } \\
\text { (mg\% SEM) }\end{array}$ & $75.0 \pm 6.7$ & $100.9 \pm 9.8^{\star}$ & $105.4^{ \pm}-8.3^{\star}$ & $143.6^{\star} \pm 14.5^{\star}$ & $182.8 \pm 21.0^{\star \star}$ \\
\hline Ratio $\mathrm{CH} / \mathrm{TG}$ & $\underline{2.17}$ & $\underline{1.93}$ & $\underline{1.58}$ & $\underline{1.24}$ & $\underline{1.10}$ \\
\hline p compared to control group: & $\begin{aligned} \star & p<0.0 \\
\star \star & p<0.0\end{aligned}$ & & & & \\
\hline
\end{tabular}

The ratio is lower with progressive involvment of the peripheral nervous system. F.S.P.: Familial spastic paralysis; CSS: Charlevoix-Saguenay Syndrome; RL: Roussy Levy Syndrome; CMT: Charcot-Marie-Tooth. 


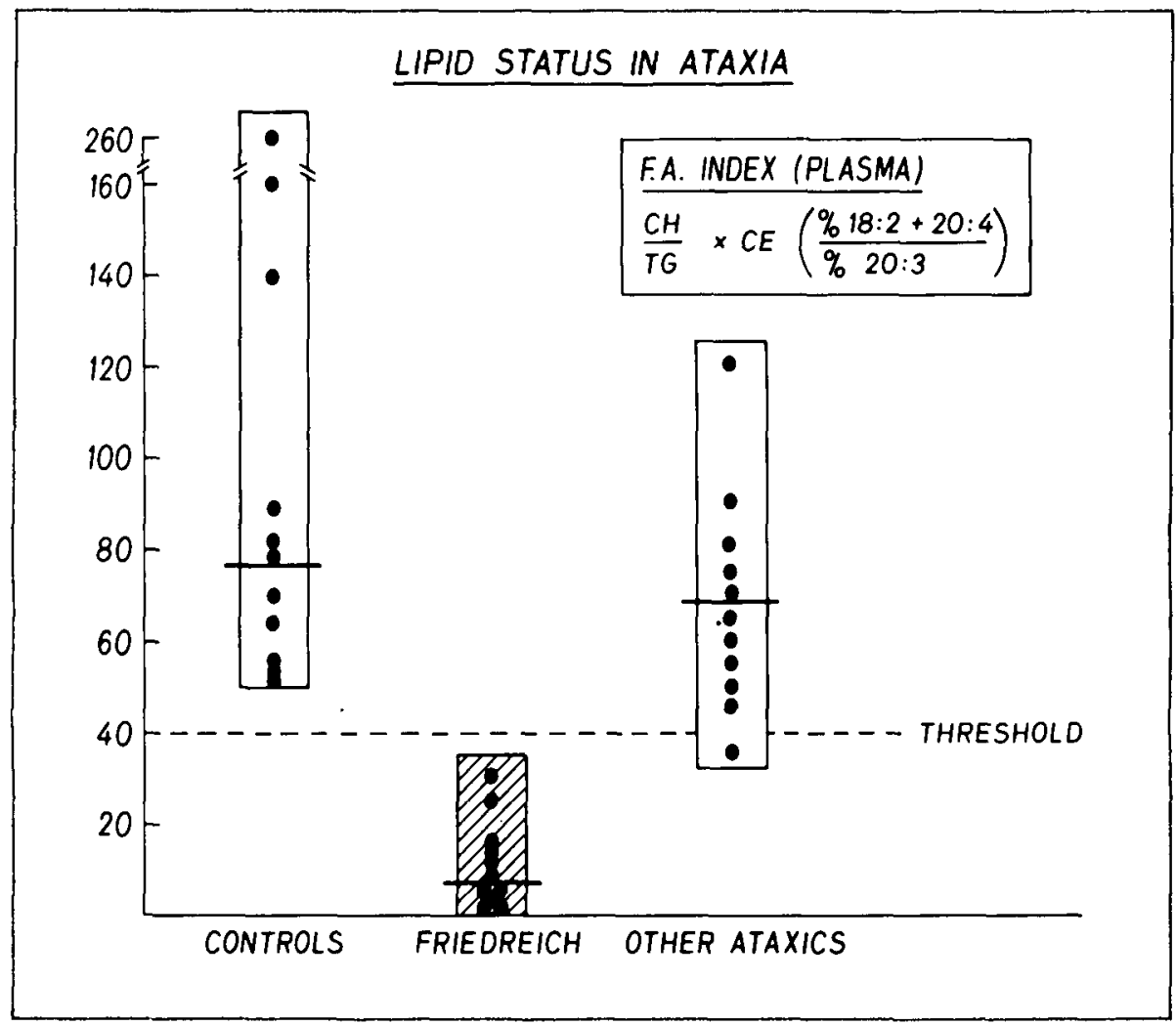

Figure 4 - A graphic representation of a combination of two combined ratios: plasma cholesterol/plasma triglycerides (see also Table 4) and 18:2+20.4/20:3, the latter an index of essential fatty acid relative deficiency. This F.A. index appears to completely discriminate between the groups.

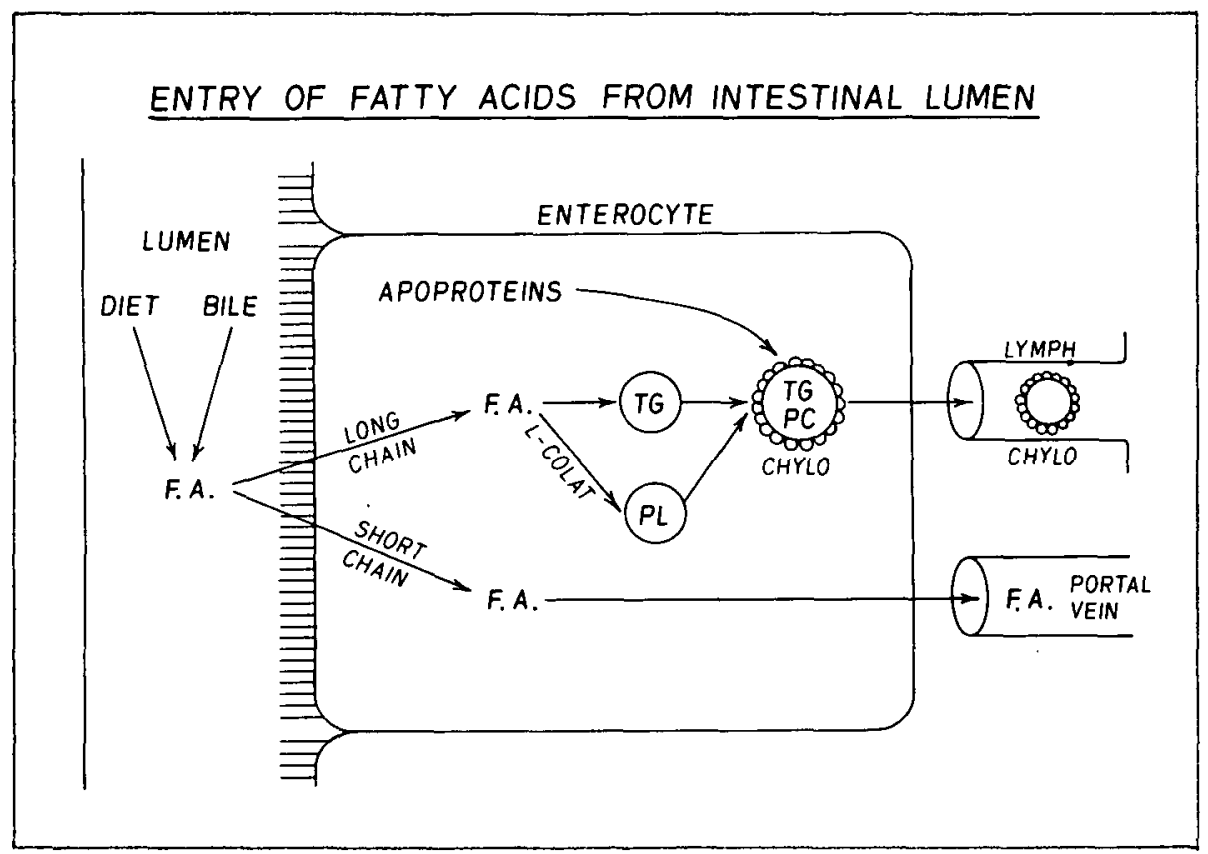

Figure 5 - Possibilities of explanations for the observed levels in phosphatidylcholine 18:2. Fatty acids (F.A.) in the intestinal lumen originate from the diet or the bile. They are incorporated to phospholipids (PL) by an enzyme linoleyl-CoA-1-acyl-glycero-3-phosphoryl choline transferase (L-COLAT). The activity of that enzyme was measured in 6 Friedreich's patients $(6.1 \mathrm{I} \pm 2.1 \mathrm{x}$ 10-4 S.A.) and 6 normal control subjects $(5.61 \pm 2.4 \times 10.4$ S.A.) and found not to be different. (St-Pierre and Barbeau, 1980 unpublished results).
Not all patients show the abnormalities mentioned above, however a pattern emerges in the group taken as a whole: the cholesterol/triglyceride ratio (Table 4) tends towards reversal of normal, more so in the presence of peripheral neuropathy, and this is accompanied by a tendency towards a relative insufficiency in cholesteryl esters polyunsaturated fatty acids (18:2 and 20:4). When these two ratios are combined, a clear difference becomes apparent between the various groups (Fig. 4) and, in combination with the low lipoprotein lipase and LCAT, indicates that lipids (particulary linoleic acid) are indeed involved in some cases of Friedreich's disease. The F.A. Index, so described, appears to discriminate totally between the normal control subjects $(n=11)$, the "other ataxics" $(n=11)$ and the Friedreich's patients $(n=11)$. However, much larger numbers will be necessary to confirm this observation and give it some diagnostic value.

Two questions can be raised from these findings: where does the relative linoleic acid deficiency come from? and how does it affect cell membranes, particularly at the mitochondrial level? A deficiency in linoleic acid (18:2) can originate from a deficient diet, from low bile 18:2 or from impairment in the incorporation of the fatty acid in the intestinal wall or-in the liver (Fig. 5). There is no data on the diet of ataxic patients, but there is no obvious reason to think that their diet is different from that of control subjects, except during episodes of diarrhea, or in the presence of malabsorption syndromes like those recently described by Elias et al (1981). Moreover, Vit. E levels in Friedreich are only slightly decreased in concentration (Filla et al, 1979). To investigate actual incorporation, we studied the activity of the enzyme linoleyl CoA-1-Acyl-glycero-3-phosphoryl choline transferase (L-COLAT), but found it to be normal. However, the relative affinity for 18:1/18:2 was not determined. It is indeed known that this enzyme can be abnormal in its affinity, if not in its level of activity.

The last possibility mentioned is a decrease in bile phospholipid linoleic 
acid (18:2). In unpublished studies (Huang, Barbeau and Davignon, 1982, unpublished) phosphatidyl choline 18:2 was indeed found to be markedly decreased in the bile of 3 patients with Friedreich's disease. Thus it may be at that level that further studies should be carried out (see infra).

Given that apparent 18:2 deficiency in phosphatidyl choline and in cholesteryl-esters, it was to be expected that membrane phosphatidyl choline 18:2 would also be decreased: this was indeed found by Huang and collaborators (1980), thus supporting the hypothesis of a decreased cell pool of 18:2. No data has yet been obtained on the fatty acid composition of mitochondrial membrane components in Friedreich's disease, but it is recalled that some of these components, particularly cardiolipin, are normally very rich in linoleic acid (over 50\%), whose turnover in this compound is extremely rapid (Landriscina et al, 1976). Two other important components of the membranes derive from 18:2: lipoic acid and prostaglandins (for review of these aspects, see Barbeau, 1980).

Changes in cell or mitochondrial membrane fatty acid composition can be translated into major modifications in two directions, first in "membrane fluidity", and secondly through interference with enzyme functions within the mitochondria. Some evidence for membrane fluidity modification have been presented in Friedreich's disease (Butterfield and Markesbery, 1980) but the changes are minimal. No doubt, if the modifications are in the same direction, they would have been much more evident if measured in the mitochondrial membrane. In Friedreich's disease an increase in membrane "rigidity" is expected from the $18: 2$ concentrations. Because of its influence on the structure of the phospholipids, the proportion of linoleic acid affects the transfer of substances through membranes (Launay et al, 1981). This may be the mechanism explaining the defect in glucose transport in Friedreich's disease (Tolis et al, 1980; Purkis et al, 1981). There is also some evidence that specialised

\section{MEMBRANE LINOLEATE AND CELL ENERGY}

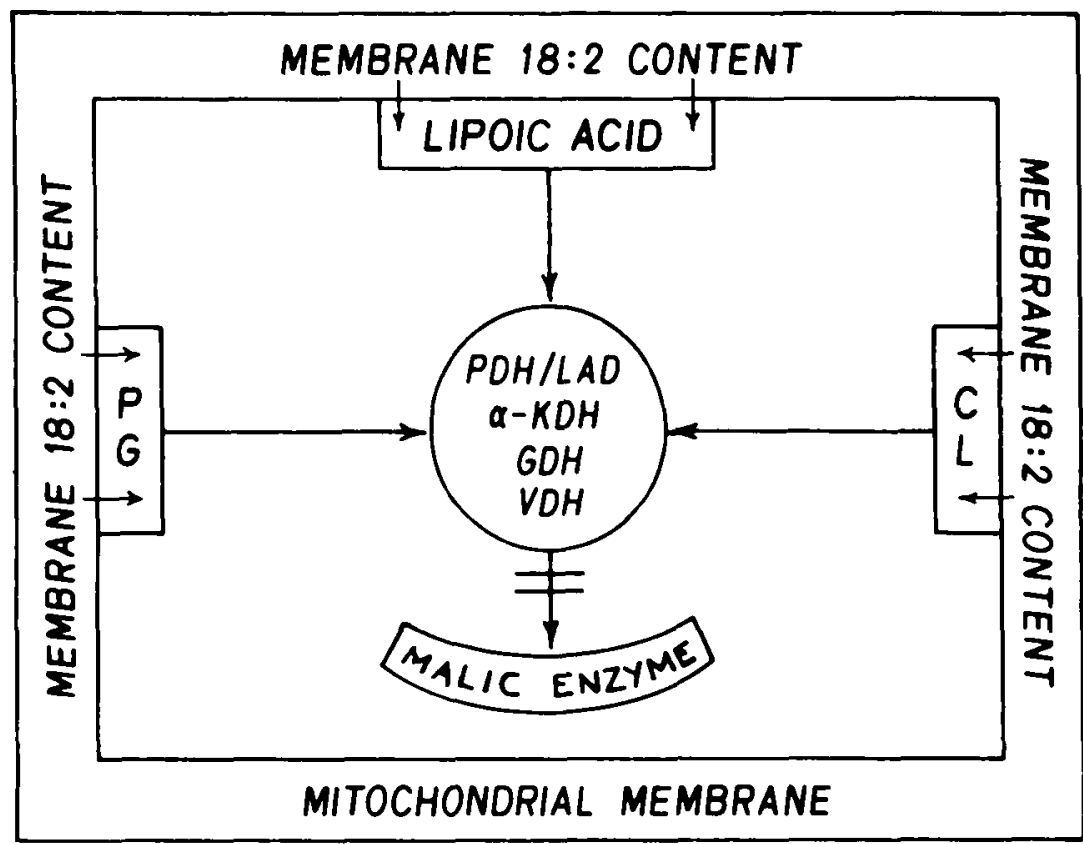

Figure 6 - Effect of changes in membrane 18:2 content upon mitochondrial matrix enzyme activities. PG: prostaglandins: $\mathrm{CL}$ : cardiolipin; PDH/LAD: pyruvate dehydrogenase/lipoamide dehydrogenase complex; $\alpha$-KDH: $\alpha$-ketoglutarate dehydrogenase: VDH: valine dehydrogenase.

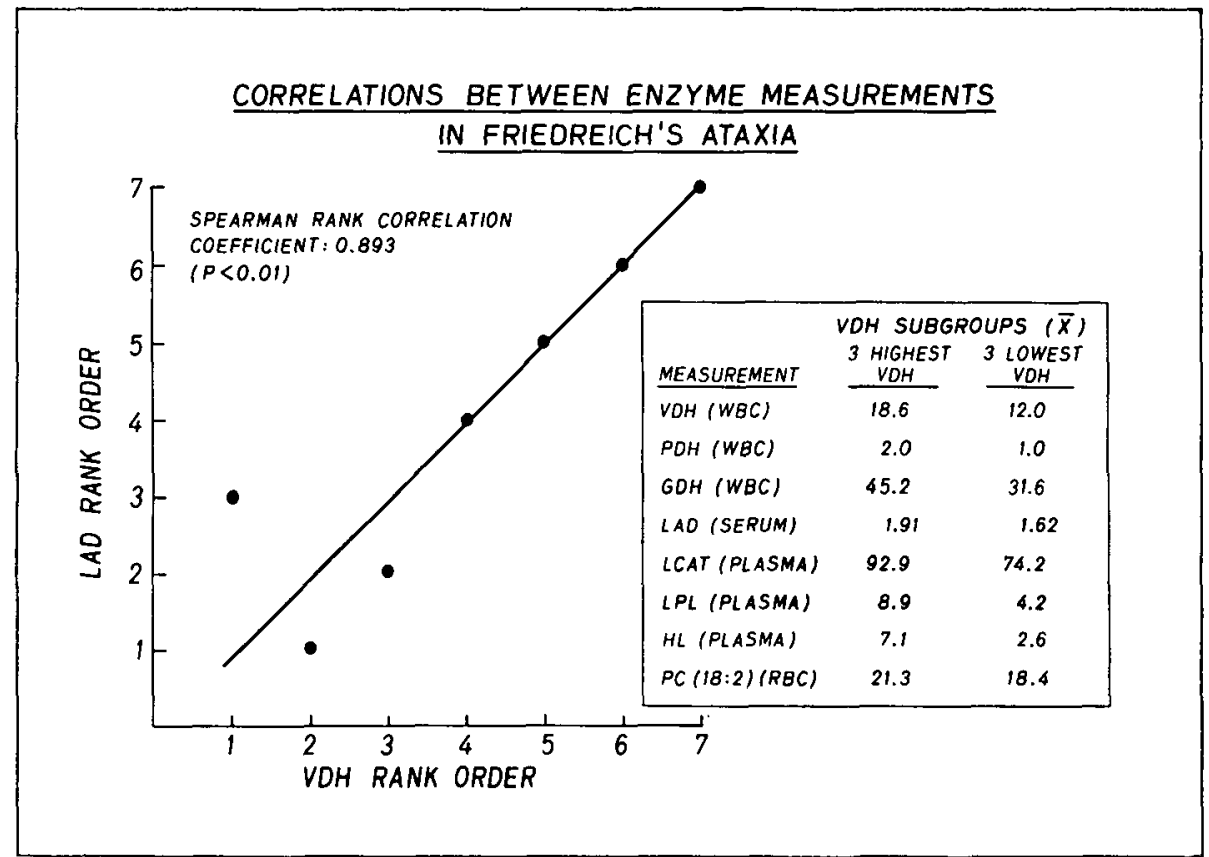

Figure 7 - Correlations between enzyme measurements in 7 patients with Friedreich's ataxia where all the following enzymes have been measured: VDH: valine dehydrogenase; PDH: pyruvate dehydrogenase; GDH: glutamate dehydrogenase; LAD: lipoamide dehydrogenase: LCAT; lecithin: cholesterol acyl transferase; LPL: lipoprotein lipase; HL: hepatic lipase, PC/RBC: 18.2 content in red blood cell phosphatidyl choline. In this correlation the activity of VDH served as the basis of division of the sub-groups. 
membrane polyunsaturated fatty acids play an important role in myelinogenesis, possibly in both the developmental and regenerative process. (Yao and Dyck, 1979).

Cell membrane 18:2 content (particularly mitochondrial membrane $18: 2$ content) can also play a role in the control of inner membrane and matrix enzymes (Fig. 6), as we reviewed previously (Barbeau, 1980). New data on interrelations between $18: 2$ and pyruvate dehydrogenase is presented by Loriette et al, (1982 this issue) and confirms the previously noted correlation.

Linoleic. acid content can thus be related to the functioning of a large number of enzymes whose activity may be secondarily reduced, either through direct interference, or through a defect in the synthesis or availability of lipoic acid (Carreau et al, 1977). A remarkable correlation between the red blood cell membrane 18:2 content and each of the mitochondrial enzymes studied was observed in 7 patients in whom we could measure all the enzymes previously reported as abnormal. (Fig. 7) From these studies we conclude that a defect in $18: 2$ availability or incorporation either from the intestine, or from the liver, can secondarily affect many of the enzymes essential to cell energy production, whose activities would be proportionally reduced.

Again we must ask: is the 18:2 deficiency, particularly within cell and mitochondrial membranes, a "primary event" in Friedreich's disease?

\section{A) Arguments against}

1. Not universal. The insufficiency in 18:2, although present to some degree in most patients with Friedreich's disease, is definitely not present in all, at least as measured in the blood. Final resolution of this problem awaits determination of the fatty acid content of mitochondrial membrane components.

2. Genetic pattern. It is still too early at this stage to draw any conclusions as to the genetic pattern of the lipid abnormalities described. 3. Not specific. A deficiency in 18:2 within the CE and PC fractions is not specific to Friedreich's disease. It has been reported to various degrees in Refsum's disease, in Bassen-Kornzweig's disease and in a variety of genetic polyneuropathies. Low 18:2 has also been claimed to be present in multiple sclerosis.

4. Site of defect not identified. The site of origin of the 18:2 defect is still conjectural. At the present time I would tend to favour a deficiency from bile lecithins, at certain times made worse by malabsorption or diet inadequacies.

\section{B) Arguments for}

1. Amplitude of defect: When present, the 18:2 deficiency is of sufficient amplitude to cause major changes in the activity of cell enzymes as well as modifications of consequence in important membranes, and their ability to transport substrates like glucose, and possibly amino-acids.

2. Compatible with physiopathology: The above described abnormalities are quite compatible with the postulated mechanisms responsible for some of the symptoms of Friedreich's ataxia, particularly if a cell energy production deficit results secondarily.

\section{C) On balance}

A deficiency in linoleic acid (18:2) cannot be the "primary event" in Friedreich's disease, and therefore a search for a block in incorporation of linoleic acid into chylomicrons or at the liver level is not a major priority. On the other hand the contribution of changes in essential polyunsaturated fatty acids, particularly at the membrane level, may be an important factor in the pathophysiology of some of symptoms, mainly the polyneuropathy.

\section{(C) THE "ENERGY DEFECT HYPOTHESIS"}

The hypothesis can be stated thus: "The primary event in Friedreich's disease is related to an enzymatic defect in the production of energy within mitochondria". In 1980, I reviewed in detail the evidence in favour of an energy deficit in Friedreich's disease (Barbeau, 1980). The data supporting this contention is illustrated in Fig. 8 and summarized in the legend. There is thus a wealth of evidence to support the hypothesis first proposed for polyneuropathies in general by Spencer and co-workers (1979), and we will not elaborate more at this time. Suffice it to point out that a postulated block has been located at many levels in the tricarboxylic acid cycle, but none of these partial blocks has been shown to be the "primary event". I have discussed above the findings relating to the $\mathrm{PDH}$, to $\alpha-\mathrm{KGDH}$ and to VDH, all of which could be secondary to a deficiency in lipoic acid or in mitrochondrial membrane fatty acids (or to some other factor altering membrane fluidity). A partial block in these enzymes, particularly if all are involved at the same time, would be sufficient to reduce energy production by the Krebs cycle, probably creating a need for alternate substrates. Since the oxidation of pyruvate, in these patients, is also reduced, only fatty acids or amino acids could serve as needed substrates. In an animal model of ataxia, thiamine deficiency, Butterworth and collaborators (1979) demonstrated a similar mechanism where the amino acids glutamate, GABA and aspartate served as partial substrate to compensate for a slow-down in pyruvate metabolism. We have postulated that this mechanism is present in Friedreich's disease and have indeed shown that there is a marked reduction in glutamate, aspartate and GABA in cerebellar tissues in Friedreich's disease (Huxtable et al, 1979). Similar patterns have been found in some cases of olivopontocerebellar atrophy by Perry et al, (1978) and in the spinal cord of spino-cerebellar degeneration by Robinson (1968). An added complication exists in Friedreich's disease. The flow from $\alpha$-keto glutarate to glutamate is further impaired by a relative deficiency in glutamate dehydrogenase (GDH) (Barbeau et al, 1980). In order to supply the added substrate for energy production, Friedreich patients must draw from the reserve (and possible neurotransmitter) pools of glutamate and GABA through the GABA shunt (to succinate).

All of these restrictions and changes 


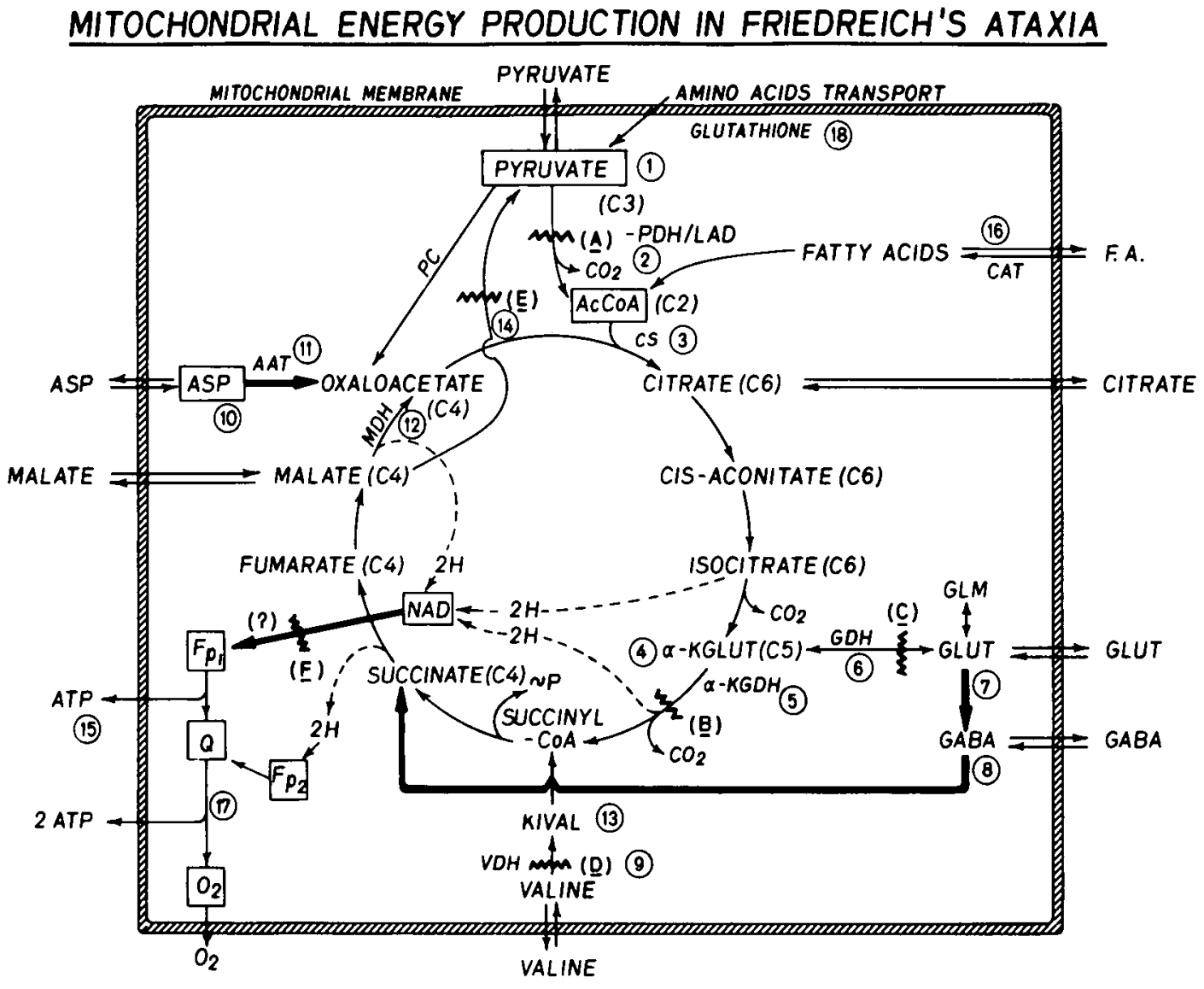

Figure 8-Energy production within the mitochondria in Friedreich's ataxia and postulated blocks.

A. Individual findings

1. Pyruvate resting levels are normal. Increase abnormally after glucose load in some but not all cases.

2. $P D H / L A D$ : PHD activity in muscle fibroblasts and platelets low in some but not all cases. LAD activity low in serum of most cases, but not all.

3. Citrate synthase activity normal or elevated

4. $\alpha$-ketoglutarate in serum: slightly elevated levels

5. $\alpha-K G D H$ : decrease in activity $(\sim 30 \%)$ in some, but not all cases.

6. GDH: decrease in activity $(20-40 \%)$ in some, but not all cases

7. Glutamate: marked decrease in concentration in some tissues.

8. GABA: marked decrease in concentration in some tissues.

9. $V D H$ : decrease in activity $(15-40 \%)$ in some, but not all cases.

10. Aspartate: marked decrease in concentration in some tissues.

11. AAT: (amino acid transferase): activity normal.

12. $M D H$ : (malate dehydrogenase): mitochondrial and cytosolic activities are normal.
13. KIVAL: serum and urine branched-chain $\boldsymbol{x}$-keto acids elevated, particularly KIVAL and KICAP.

14. Malic enzyme: normal cytosolic activity. Some patitients with marked decrease in mitochrondrial ME activity in tissues and fibroblasts.

15. ATP production decreased in patients, with apparent uncoupling of phosphorylation.

16. $C A T$ (carnitine acetyl transferase): normal activity.

17. Respiratory chain: no data available.

18. Glutathione reductase: normal activity.

B. Postulated blocks (Partial) smm
A. $P D H / L A D$ : Pyruvate dehydrogenase complex
B. $\alpha-\mathrm{KGDH}$ : alpha-ketoglutarate dehydrogenase complex
C. $G D H$ : glutamate dehydrogenase
D. $V D H$ : valine dehydrogenase complex
E. $M E$ : malic enzyme (mitochondrial)
F. NAD: energy output by mitochondria through nicotinamide dinucleotide.

would tend to decrease the transfer of $\mathrm{H}_{+}$atoms to NAD and thence to the respiratory chain, particularly the $2 \mathrm{H}_{+}$ from the oxidation of $\alpha$-keto glutarate. Thus total energy production would be decreased by an amount approximately equivalent to the inhibition of the above noted enzymes, and this even despite the shunting mechanism from amino acids. Finally it should be mentioned that protoporphyrin levels were found to be elevated in Friedreich's disease (Morgan et al, 1979). This could be due to inhibition of ferrochelatase, with resulting secondary increases in bilirubin. The enzyme ferrochelatase is also under the regulating control of mitochondrial lipids (Simpson and
Poulson, 1977). Mitochondrial electron transport and ATP production are distinct, but ordinarily tightly coupled. Substrate oxidation and oxygen consumption (respirator control) are thus limited in the absence of ADP or inorganic phosphate. The respirator control ratio (state $3 /$ state 4 ) is an indirect measure of coupling, and is reduced in 
the presence of protoporphyins (Stumpf et al, 1979).

Recently another site of enzyme block has been proposed by Stumpf et al $(1981,1982)$ who found that mitochondrial malic enzyme (ME; Lmalate: NADP oxidoreductase, decarboxylating; EC. 1.1.1.40) specific activity was $10 \%$ of controls in fibroblasts from eight FA patients. Cytosolic malic enzyme was modestly increased in FA fibroblasts. Malic enzyme (Fig. 9) is an inducible enzyme whose function is still not clearly understood. It has been shown to exist in mammalian tissues in two forms: soluble (cytosolic) and mitochondrial (Henderson, 1966). In the human the cytosolic enzyme (MEc) is found in all tissues except red cells and serum. It is even present in fibroblasts. Only partial purification of the enzyme has been accomplished in mammals (Swierczynski, 1980). The molecular weight of the native enzyme was determined by gel filtration to be 264,000 . It appears that the native protein is a tetramer composed of identical molecular weight subunits. The $\mathrm{km}$ values $(\mathrm{pH}$ 7.2) for malate and NADP, were $0.125 \mathrm{mM}$ and $11 \mu \mathrm{M}$, respectively. The $\mathrm{km}$ values for pyruvate and NADPH were $4.0 \mathrm{mM}$ and $6.6 \mu \mathrm{M}$, respectively.

The mitochondrial enzyme $\left(\mathrm{ME}_{\mathrm{m}}\right)$ is seen in brain, kidney, heart muscle, liver and cultured fibroblasts. The enzyme is also a tetramer. It shows marked polymorphism in human tissue (Cohen and Omenn, 1972). Absolute activity of the various forms of $\mathrm{ME}$ vary greatly from tissue to tissue: in adrenal medulla and white adipose tissue, ME is located exclusively within the extra mitochondrial compartment. In liver, $95 \%$ of the activity is extra mitochondrial and only $5 \%$ intra mitochondrial. In heart, $30 \%$ of the enzyme activity is extra mitochondrial and $70 \%$ intra mitochondrial (Brdiczka and Pette, 1971).

The cytosolic malic enzyme is readily responsive to nutritional influences such as to high carbohydrates and to starvation (low proteins diets). It is also responsive to thyroxin and insulin in vitro through induction of mRNA (Siddiquit et al, 1981). This latter effect can be blocked by glucagon. On the other hand, the mitochondrial malic enzyme but not the cytosolic enzyme is activated by succinate and aspartate (Frenkel and Cobo-Frenkel, 1973). The activity of this enzyme may thus increase rapidly under conditions which would favour accumulation of intermediates of the Krebs cycle. Conversely the activity of mitochondrial malic enzyme decreases in the face of a deficiency in Krebs cycle intermediates.

The mitochondrial malic enzyme, like the cytoplamic form, catalyses the oxidative decarboxylation of malate to pyruvate with the formation of NADPH. However, in contrast to its cytoplasmic counterpart which readily catalyses the reverse reaction, the mitochondrial malic enzyme is virtually inactive in catalysing the reductive carboxylation of pyruvate. The $\mathrm{kms}$ for malate are $2.5 \mathrm{mM}$ and $0.5 \mathrm{mM}$ for the mitochondrial and cytosolic enzymes, respectively, while the $\mathrm{kms}$ for pyruvate are $5.0 \mathrm{mM}$ and $2.3 \mathrm{mM}$ for the same enzymes (Simpson and Estabrook, 1969). This is compatible with a NADPH shuttle across the mitochondrial membrane to supply reducing equivalents for the synthesis of lipids and possibly for $11 \beta$ hydroxylation of steroids in the adrenals (Simpson and Estabrook 1969). The most striking difference between the two enzymes is in the ratio of the maximum initial velocities for the forward and reverse reactions. The ratio is 50 for the mitochondrial enzyme and 2.5 for the cytosolic enzyme. This suggests that, whereas the mitochondrial enzyme can preferentially operate in the forward reaction, the cytosolic enzyme might operate in the reverse reaction to produce malate from pyruvate and bicarbonate. This was recently confirmed by Swierczynski (1980).

From these considerations, a number of functions have been postulated for malic enzyme:

(1) lipogenesis, through its production of NADPH

(2) gluconeogenesis: pyruvate to malate (thermodynamically unfavorable)

(3) net glutamine oxidation to pyruvate from the intestinal mucosal mitochondria (Sauer et al, 1979)

(4) Formation of alanine from skeletal muscle in conditions of fasting or exercising (Lee and Davis, 1979; Goldberg and Odessey, 1972)

In conclusion, one could summarize the activity of the cytosolic enzyme (MEc) as that of a replenishing (anaplerotic) function for citric cycle intermediates, and the activity of the mitochondrial enzyme $\left(\mathrm{ME}_{\mathrm{m}}\right)$ as that of a safety valve, for the removal of excess concentrations of the same intermediates usually produced from aminoacids or from lipids. The cytosolic enzyme is inducible by large intakes of carbohydrates in the diet and inhibited by dietary lipids, while $M E_{m}$ is activated by succinate and aspartate. Conversely starvation inhibits $\mathrm{ME}_{\mathrm{c}}$, and decreases in Krebs cycle intermediates inhibit (or down regulate) $\mathrm{ME}_{\mathrm{m}}$.

In the light of this short review of malic enzyme function, we can now analyse the significance of the report by Stumpf et al, (1982) on decreases in mitochondrial malic enzyme activity in Friedreich's disease. In the first part of their paper the authors report polarographic (oxygraph) assays indicative of pyruvate-malate metabolism abnormalities. This is compatible with a disturbance in the postulated malic enzyme defect, but the same changes would be found if there were a PDH deficiency in these patients. Moreover the variation in polarographic assays between muscles are striking and surprising. In fibroblasts, the mitochondrial malic enzyme specific activity was found to be low. "Corrected activity" in Friedreich's was $10 \%$ of controls, but "uncorrected activity" of $\mathrm{ME}_{\mathrm{m}}$ was $27 \%$ of controls*. Stumpf and collaborators (1982) were unable to measure any activity of malic

\footnotetext{
Note:* It is difficult to see why a correction factor of $166 \%$ was applied in the case of Friedreich's fibroblasts, while only of $1-6 \%$ in normal and abnormal controls, particularly in light of the statment that LDH (a measure of cytosolic contamination) in the mitochondrial fraction was the same in FA and control groups. This may be an artefact of the correction formula used which incorporates the values of succinate: cytochrone $c$ reductase (SCR), which are lower in Friedreich (due to other factors).
} 


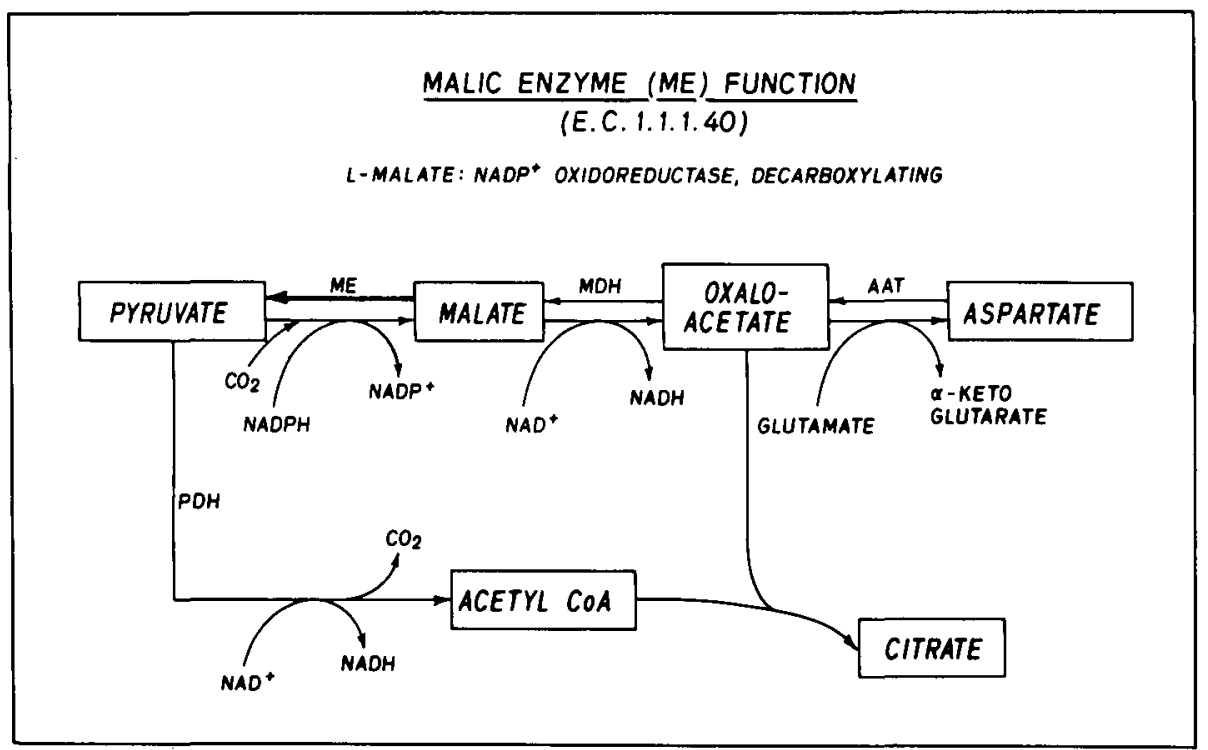

Figure $9-$ Site of action of malic enzyme. In preliminary studies we measured cytosolic malic enzyme activity in leukocytes of patients with typical Friedreich's disease $(n=7)$ and sex/age matched normal controls $(n=8)$ by a modification of the method of Lin and Davis (1974). Spectrophotometric readings were carried out at $340 \mathrm{~m} \mu$ and $26^{\circ} \mathrm{C}$. The controls had values of $6.68 \pm 1.92$ (mean $\pm \mathrm{SD}$ ), and the patients $8.51 \pm 3.26 \mathrm{n} \mathrm{Mole} / \mathrm{min} / \mathrm{mg}$ protein. The difference was not significant (Charbonneau, M. and Barbeau, A.; 1982, unpublished studies). Polyacrylamide gel electrophoresis of the sonicated leukocyte showed only faint staining in a band corresponding to MEm in both normal and Friedreich's tissue.

\section{TABLE 5}

TAURINE IN FRIEDREICH'S DISEASE mean $\pm S D$

\begin{tabular}{|c|c|c|}
\hline & CONTROL & FRIEDREICH \\
\hline Plasma ( $\mu$ mole $/ 100 \mathrm{~m} 1$ ) & $4.39 \pm 2.93$ & $4.38 \pm 3.36$ \\
\hline Urine $\left(\mu \mathrm{mole} / \mathrm{min} / 1.73 \mathrm{~m}^{2}\right.$ & $47.2 \pm 46.1$ & $91.5 \pm 67.0^{\star}$ \\
\hline $\operatorname{CSF}(\mu \mathrm{mole} / \mathrm{L})$ & $8.9 \pm 4.0$ & $8.9 \pm 4.2$ \\
\hline $\begin{array}{l}\text { Renal clearance } \\
\qquad\left(\mathrm{ml} / \mathrm{min} / 1.73 \mathrm{~m}^{2}\right)\end{array}$ & $14.2 \pm 3.8$ & $58.9 \pm 65.5^{\star}$ \\
\hline $\begin{array}{l}\text { Cerebellar hemispheres } \\
(\mu \mathrm{mole} / \mathrm{g} \text { wet weight })\end{array}$ & $2.2 \pm 1.0$ & $3.8 \pm 0.6^{\star}$ \\
\hline $\begin{array}{l}\text { Anterior vermis } \\
(\mu \text { mole/g wet weight })\end{array}$ & $1.6 \pm 0.7$ & $2.6 \pm 0.1 *$ \\
\hline $\begin{array}{l}\text { Dentate nucleus } \\
\text { (umole/g wet weight) }\end{array}$ & $1.3 \pm 0.7$ & $3.5 \pm 3.2$ \\
\hline $\begin{array}{l}\beta-\text { alanine in urine } \\
\left(\mu \mathrm{mole} / \mathrm{mm} / 1.73 \mathrm{~m}^{2}\right)\end{array}$ & $0.8 \pm 1.3$ & $6.4 \pm 11.5$ \\
\hline
\end{tabular}

Data from Lemieux et a1., 1976; Huxtable et al., 1979. enzyme in the leukocytes of their patients. In similar studies (Fig. 9) we found sufficient activity to show that there is no difference in total (probably cytosolic) activity between patients and controls.

The significance of these new findings will depend on the interpretation one can give to such changes in $\mathrm{ME}_{\mathrm{m}}$ activity, assuming they are confirmed in the pertinent tissues (dorsal root ganglia, posterior columns, vermis and heart). Stumpf et al, (1982) appear to accept that mitochondrial ME can regulate the flow in both directions: from pyruvate to malate and inversely, but this is contrary to all studies of relative $\mathrm{kms}$ in normal conditions (see discussion above).

Even if $\mathrm{ME}_{\mathrm{m}}$ were anaplerotic to the Krebs cycle, one would have some problems in accepting the premise that such a deficiency could cause Friedreich's ataxia as we know it. The cardiac abnormality and muscle weakness would be relatively easy to explain because of the fair homogeneity of the tissues, but it is difficult to imagine that malic enzyme (which is present in all areas of the brain) could be totally deficient selectively only in some areas. Such a major defect in all neurons could hardly escape causing more widespread pathological damage, if it is the "primary event". In my view, mitochondrial malic enzyme activity is indeed decreased in some patients but, because I consider the role of $\mathrm{ME}_{\mathrm{m}}$ to be a safety valve for Krebs cycle intermediates towards pyruvate and alanine, this decrease should be considered a consequence of the energy defect, not a cause. In other words, I think mitochondrial malic enzyme is "down regulated" in Friedreich's disease (because of the other partial defects in PDH, VDH, $\alpha \mathrm{KGDH}$ and GDH), but not genetically deficient. This hypothesis should be testable by studying the inducibility of $\mathrm{ME}_{\mathrm{m}}$ after aspartate, succinate or linoleic acid (see above) in patients and controls.

In summary, to the question of whether a $M E_{m}$ defect is the "primary event", the following arguments can be marshalled:

\section{A) Arguments against}

1. Not compatible with physio- 
pathology: this is the main argument against this hypothesis. If $\mathrm{ME}_{\mathrm{m}}$ activity is really $10 \%$ of controi in all cells (as the "corrected" fibroblast data would imply) much more generalized neurological damage would be expected, and much earlier in the evolution of the disease, because malic enzyme is situated at a crucial metabolic crossroad. Cases with clinical onset at age 16-17 would be very hard to explain.

2. Specificity: not yet verified.

B) Arguments for

1. Apparent universality of finding in fibroblasts.

2. Site of defect well identified (if findings are confirmed).

3. Amplitude of defect is sufficient to be of genetic origin.

\section{C) On balance}

I personally believe that the malic enzyme deficiency is not the "primary event" in Friedreich's disease, but a "down regulation" of the enzyme as a consequence of previously noted and discussed impairment at many steps of the cell energy production chain. This down regulation would be necessary in such conditions to preserve the new citric acid cycle intermediates originating from alternate substrate amino acids. At any rate, the most important findings of Stumpf and collaborators should stimulate detailed studies. Even without a defect in mitochondrial malic enzyme, there is strong evidence (reviewed by Barbeau, 1980), that many of the symptoms of Friedreich's disease are secondary to a deficiency in energy production, a finding on which all authors agree.

\section{(D) THE TAURINE HYPOTHESIS}

The hypothesis can be stated thus: "The primary event in Friedreich's disease is related to a deficiency in the retention of the amino acid taurine". The initial observation of increased taurine and $\beta$-alanine urinary excretion was made in the course of the preliminary survey of patients with Friedreich's disease (Lemieux et al, 1976) (Table 5). The apparent taurine loss was confirmed through studies

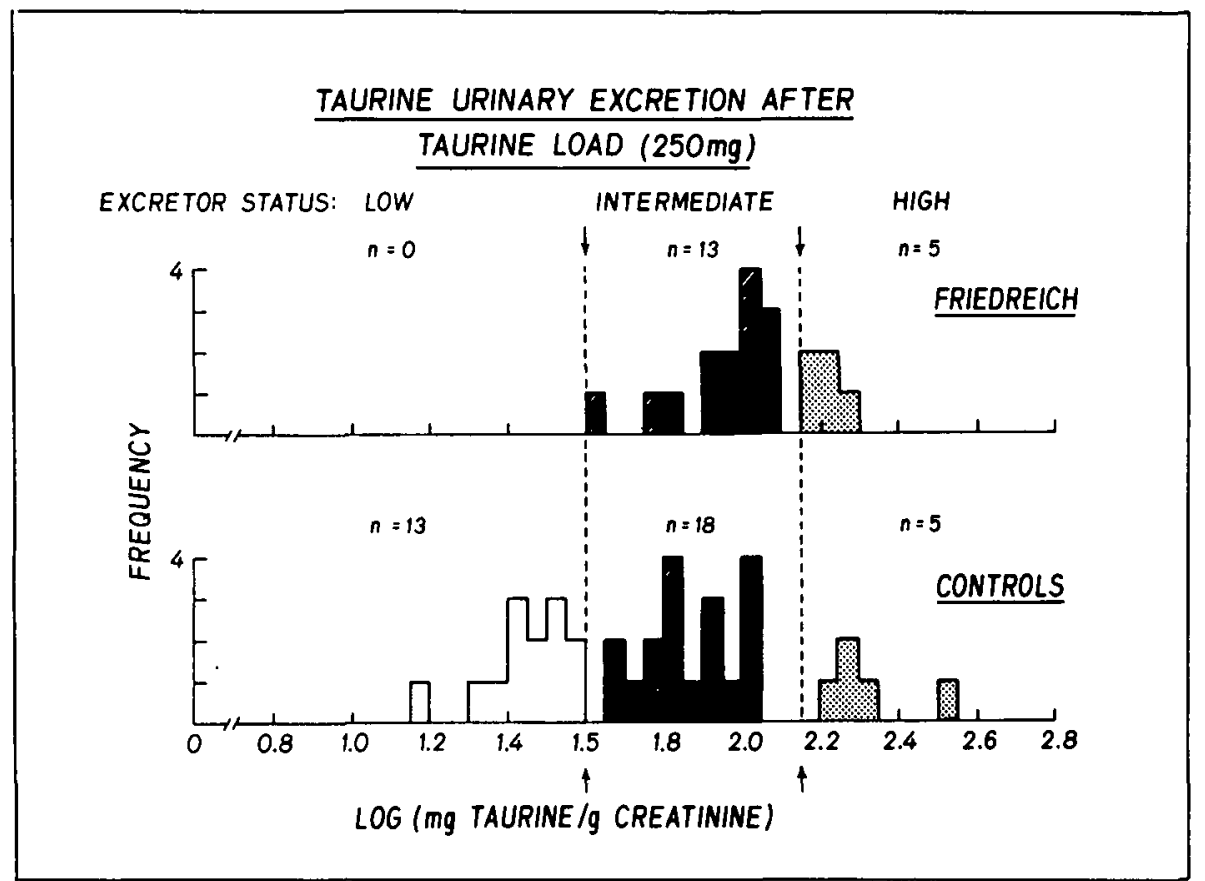

Figure 10 - Taurine urinary excretion after an oral taurine load of $250 \mathrm{mg}$. None of the Friedreich patients fall into the low excretor status.

where patients were given a uniform load of taurine $(250 \mathrm{mg})$, thereby minimizing the effect of the previous diet, and timed urine samples collected (Filla et al, 1979). Again the ataxic subjects excreted twice as much of the taurine load as the age-matched controls. A high urinary excretion of taurine has been observed in a number of physiological as well as pathological conditions, particularly after stress, corticosteroids, "idiopathic" scoliosis, and familial cerebellar dyssynergia (for reviews see: Jacobsen and Smith, 1968; Huxtable and Barbeau, 1976; Barbeau and Huxtable, 1978; Huxtable and Pasantes-Morales, 1982).

It thus appeared that ataxic patients could not retain taurine as well as normal subjects. Assuming a normal glomerular filtration rate, because of the normal blood concentrations, it looked as if the defect could be situated in reuptake mechanisms. However our initial studies did not appear to confirm this hypothesis. Taurine uptake in platelets (Filla et al, 1978) and later in fibroblasts (Melançon et al, 1980) gave average results within the normal control range under the conditions employed. Following the observations of Goodman and collaborators (1980) who postulated three taurine excretor classes under genetic control, we reinvestigated this problem (Barbeau et al, 1982, this issue). As seen in Fig. 10 the striking finding, after a $250 \mathrm{mg}$ taurine load, is the total absence of "low excretors" as compared to the control group. The Friedreich patients behave as if their tubular reuptake system at low concentrations of taurine did not function properly. This same pattern was probably present in fibroblasts of Friedreich's patients in the study by Melançon (Fig. 1 of Melançon et al, 1980), but went unnoticed because the two means were similar.

To explain these findings we postulated (Barbeau et al, 1982, this issue) an impairment of $\beta$-amino acid permeation on a low-km uptake system at the kidney tubule luminal membrane. This is illustrated and explained in Fig. 11. Thus we propose that patients with Friedreich's disease lack proper regulation of the high affinity-low capacity (TH system) uptake mechanism for taurine in the brush border membrane of kidney tubules.

There is every reason to believe that the same defect could be present in fibroblasts and in the intestinal brush border membrane, but these aspects 


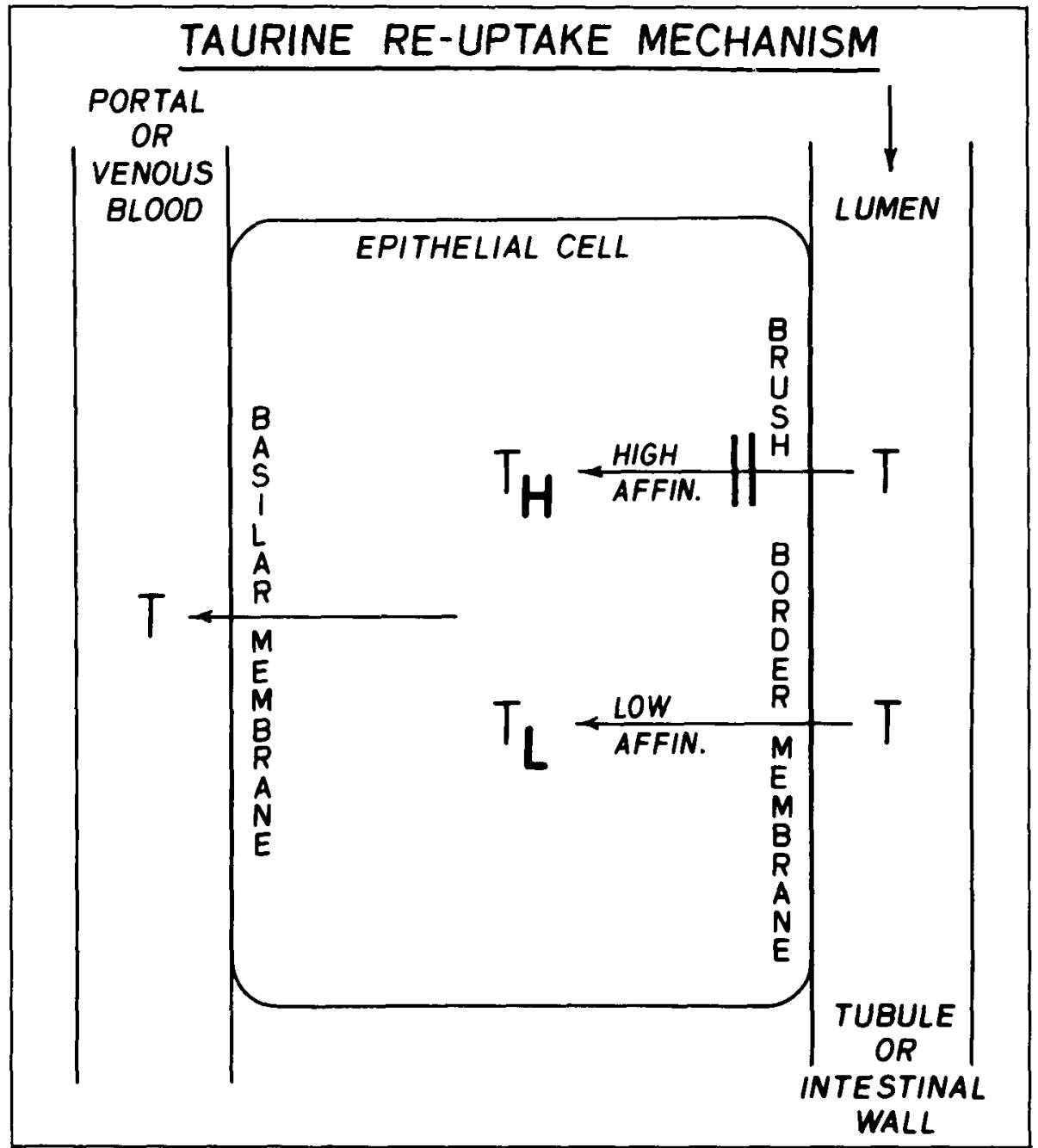

Figure $11-$ Site of the postulated taurine uptake effect in Friedreich's disease. In the brush border membrane of the tubule, there exist two uptake systems of taurine: one with a high affinity (low $\mathrm{Km}$ ) and a small capacity (the TH system), another with low affinity (high $\mathrm{Km}$ ), but high capacity (the TL system). The postulated defect in Friedreich's disease would affect specifically the TH system, which functions preferentially at low concentrations. At high concentrations the TL system takes over and can mask the defect in the TH system.

have not yet been investigated properly.

The loss of taurine in the urine after a taurine load appears to follow a genetic pattern. As illustrated in Fig. 12, the parents of patients (obligate heterozygotes) have an excretion pattern intermediate between controls and patients. Furthermore none of the parents are low or high excretors, all being classified as "intermediate" excretors. These findings indicate that the postulated uptake defect in taurine is closely and directly related to the "primary event", since it appears in all the cases so far tested and since it follows the expected genetic pattern. Many more studies will be required before this hypothesis is confirmed. Again it is appropriate to ask the same questions concerning the relationship of the postulated taurine defect with the "primary event".

\section{A) Arguments against}

1. Specificity: higher than normal urinary excretion of taurine have been seen in a number of entities, some not neurological and even in some normal subjects. It is not known, however, if the TH system is defective in these cases, because it is at low substrate concentrations that the defect results in a tissue deficiency. Other forms of ataxia have not yet been tested.
2. Site of exact defect and the mechanism of that defect in $\mathrm{TH}$ reuptake system have not yet been delineated.

B) Arguments for

1. Universality of the finding in all cases of Friedreich thus far tested. In other words we have not yet found a single FA patient within the low excretor group.

2. Sufficient amplitude: the defect as reported would be of sufficient amplitude to cause, over a period of years, a cumulative deficiency in the taurine pool available for osmotic and metabolic modulator functions.

3. Genetic pattern: the genetic pattern observed in taurine urinary excretion in patients and their parents is compatible with autosomal recessive transmission of the trait $\left(\mathrm{TH}_{\mathrm{F}}\right)$.

4. Compatible with physiopathology As will be seen in the next few pages, this finding is compatible with everything presently known about the biochemistry of Friedreich's disease.

C) On balance

It is my personal opinion that, of the four working hypotheses reviewed in relation to Friedreich's disease, only the Taurine Hypothesis comes close to fulfilling most of the necessary criteria for a "primary event". However this hypothesis, being the newest, is also the one least tested in other laboratories and therefore the most fragile one at this stage.

\section{PERSONAL OPINION AS TO THE ETIOLOGY AND \\ PATHOPHYSIOLOGY OF FRIEDREICH'S DISEASE}

Having thoroughly reviewed all the arguments for and against each of the four hypotheses, it is now time for us to choose and to take position in order to orient further research in our own laboratory and in our cooperating centers. This is a risky action taken only after due deliberation and to stimulate discussion. A summary of the arguments is given in Table 6.

It is seen that the taurine hypothesis is the only one compatible with all the criteria, if we accept that two still 


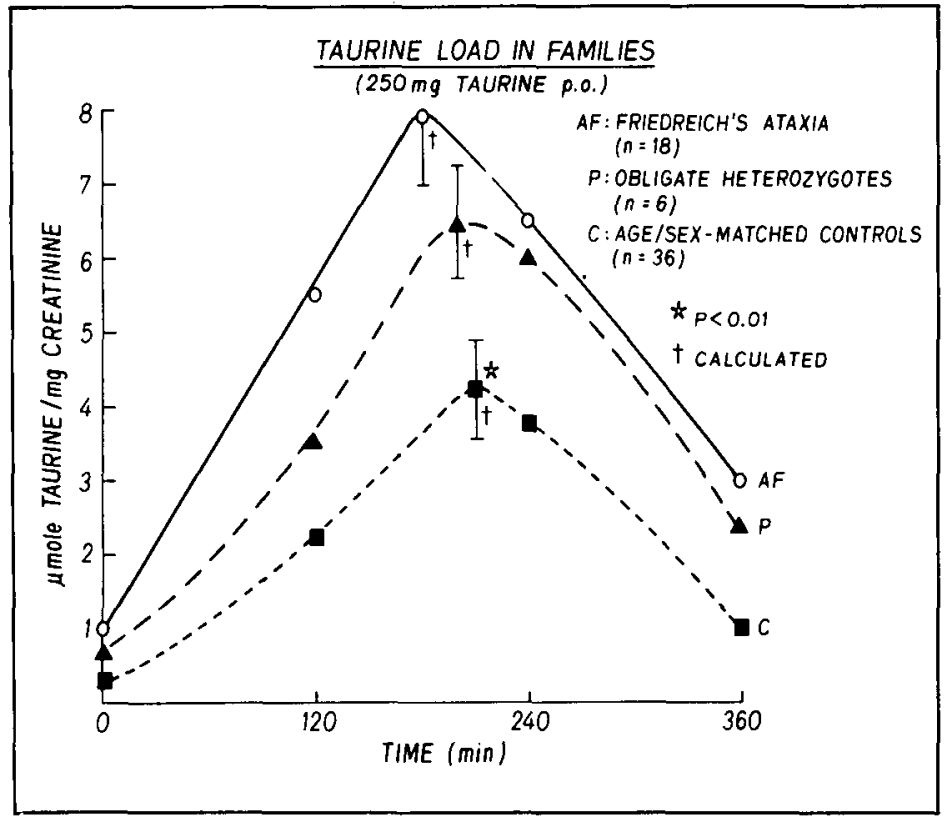

Figure 12 - Urinary excretion of taurine after a $250 \mathrm{mg}$ taurine load in patients with Friedreich's disease, their parents, and normal control subjects. The obligatory heterozygotes have intermediate values.

\section{TAURINE AND INTRACELLULLAR CALCIUM}

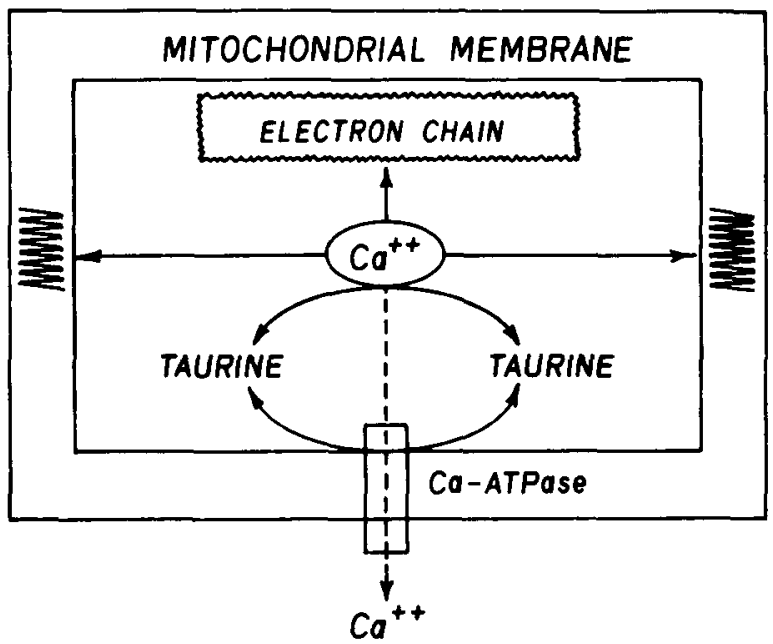

Figure 13 - Possible interaction between calcium and taurine within mitochondria. Accumulation of free calcium could cause uncoupling in the respiratory chain, and even cell damage.

TABLE 6

COMPATIBILITY OF HYPOTHESES WITH CLINICAL GENETIC AND BIOCHEMICAL CRITERIA FOR FRIEDREICH'S DISEASE

\section{ITEMS}

1. Universality

2. Amplitude

3. Specificity

4. Genetic pattern

5. Site of defect identified

6. Compatible with physiopathology

7. Compatible with biochemical criteria
a. M.E.
b. $\mathrm{PDH} / \mathrm{LAQ}$
c. $\alpha-\mathrm{KGOH}$
d. $V D H$
e. GDH
f. $18: 2$ in RBC

\section{HYPOTHESES}

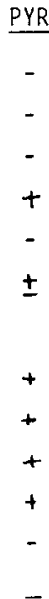

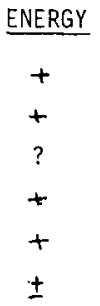

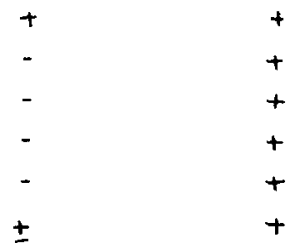

partially unknown results may be positive. The malic enzyme defect fails to account for the significant changes in $\mathrm{PDH} / \mathrm{LAD}, \alpha-\mathrm{KGDH}, \mathrm{VDH}$ and GDH in a good number of the patients and is difficult to reconcile with some of the pathological and clinical findings. The other two hypotheses are mainly rejected because of their lack of universality in typical Friedreich patients. It is also immediately evident that none of the hypotheses are mutually exclusive. Much of the evidence favouring each one can also be used in favour of the other hypotheses, and is probably an integral part of the etiologic mechanism, but at the secondary level.

In conclusion, I believe that a defect in taurine conservation is the only primary event presently known in
Friedreich's disease. If this is so, I must now try to explain how this defect is compatible with all that is known about the disease, and how it is related to the multiple biochemical defects shown to exist in Friedreich, at least in a significant number of patients. Taurine must first be shown to be distributed in the appropriate regions, and to possess mechanisms of action that, if disturbed, would be compatible with the observed 
abnormalities (clinical and biochemical).

TAURINE (2-aminoethanesulfonic acid) is an essential amino acid with little metabolic activity, in that it is not transformed significantly in humans. About half of taurine is obtained from the diet, with the rest synthesized mainly in the liver from cysteine or cysteic acid (for reviews see Huxtable and Barbeau, 1976; Barbeau and Huxtable, 1978 and Huxtable and Pasantes-Morales, 1982; unless specifically cited, the following statements by authors marked * will be found in these books). The distribution of taurine between tissues is not homogeneous. $70 \%$ of the taurine content of the body is in muscles, including the heart. This is in a relatively slow exchangeable pool. The highest concentration is in the heart followed by the kidney and then the brain where the frontal lobe has the highest level. Cysteine sulfinic acid decarboxylase (CSD) which catalyses the synthesis of taurine is mainly in the liver, followed by the kidney. In the central nervous system of the rat the cerebellum $(6.5 \mathrm{uM} / \mathrm{g}$ wet weight), cerebral cortex (7.2), striatum (8.0) and hippocampus have the highest concentrations, while the pons, medulla (2.4) midbrain (2.8) and spinal cord (1.7) have the lowest values (Lombardini, 1975). Kuriyama* et al, (in Barbeau and Huxtable, 1978) have studied the micro-distribution of taurine and of CSD in rat spinal cord. It was found that taurine is rather evenly distributed in the spinal cord, whereas the activity of CSD is higher in the dorsal half of the spinal cord $(>5$ $\mathrm{n} \mathrm{moles} / \mathrm{mm}^{3} / \mathrm{hr}$ ) than in the ventral half ( $<5 \mathrm{n}$ moles $/ \mathrm{mm}^{3} / \mathrm{hr}$ ). The highest activity of CSD was found in the dorsal part of the dorsal horn $(>25 n$ moles $/ \mathrm{mm}^{3} / \mathrm{hr}$ ).

In the brain, the heart and the kidney, taurine was found to be taken up by a high affinity, low $\mathrm{Km}$, low $\mathrm{V}$ max, low capacity system which is sodium dependent and specific for $\beta$ amino acids, and by a low affinity-high capacity system not inhibited by other $\beta$-amino acids (Hruska et al, 1978*; Chesney et al,* 1978). In kinetic studies, Lombardini* (1976) incubated various regions of the rat CNS with 35

\section{TAURINE AS REGULATOR OF AMINO-ACID TRANSPORT}

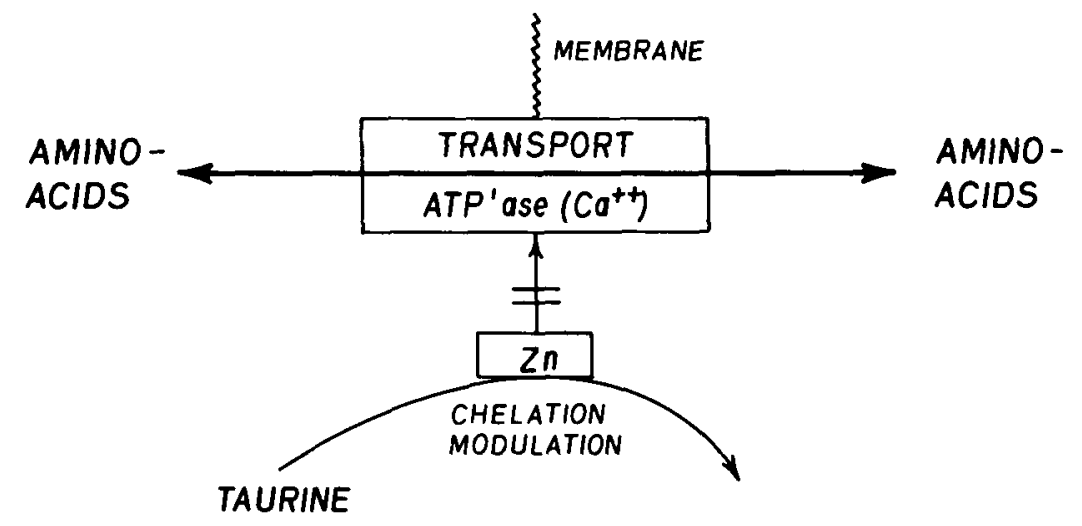

Figure 14 - Possible role of taurine as a chelator of zinc, which would affect the transport of amino acids across membranes. The combination of a zinc deficiency and of taurine deficiency could result in a severe destablization of membranes and of their transport system.

S-taurine. Considerable differences in the kinetic parameters were observed, with the lowest $\mathrm{km}(\mu \mathrm{M})$ for the spinal cord (10.8) and the highest for the cerebellum (108) and the pons-medulla (200). V max followed almost parallel lines. This suggests that the spinal cord has the greatest affinity for a possible membrane-mediated carrier system for taurine. The spinal cord, and particularly the dorsal horn, is closely correlated with taurine activity and turnover, if not concentration. Thus we have shown that taurine metabolism is indeed active in the appropriate areas involved in spino-cerebellar degenerations. What are the mechanisms of action of taurine?

Many hypotheses have been proposed to explain the various actions of taurine. They have all been reviewed previously (Barbeau et al, 1975, and the three cited volumes on taurine):

(1) Taurine may act as a modulator of electrolyte transport, particularly of calcium (Welty et al*, 1976) (Fig. 13) or by contributing to the binding of $\mathrm{Ca}++$ to intracellular organelles (Pasantes-Morales*, 1982).

(2) Taurine could be an osmotic regulator in brain and heart (Thurston et al, 1981).

(3) Taurine could act as a membrane stabilizer, particularly in excitable tissues (Gruener et $\mathrm{al}^{*}, 1976$ ).
(4) Taurine could be involved in the regulation of tissue glutamine/glutamate balance (Van Gelder*, 1976, 1978).

(5) Taurine could act as an inhibitory transmitter substance, in spinal cord and possibly in retina (Phyllis*, 1976; Pasantes-Morales*, 1982). However the neurotransmitter role of taurine is less popular now than the modulator role.

(6) Taurine could act by chelation of zinc and thus modify the ATP ase transport pump. (Fig. 14). The relationship of taurine and zinc has not received the importance it merits. This link was first proposed by Barbeau and Donaldson (1974) in relation to epilepsy. Chelation of zinc would have a stimulatory effect on Na-K-ATP ase and could account for the retention of potassium caused by taurine. A zinc deficiency is accompanied by a taurine loss in the urine. Zinc is highly concentrated in the boutons terminaux of the hippocampus mossy fibers, and in the tapetum where it is in the form of a zinccysteine complex. The same rod membrane contains high levels of taurine (Sturman et al*, 1982). A zinc deficiency mimics many of the clinical features of essential fatty acid deficiency, and can be corrected 
by $\gamma$-linolenic acid and not by linoleic acid (Huang et al, 1982).

(7) Finally, we have proposed (Barbeau*, 1982) that taurine plays a role as a modulator of sensory input in mammals.

It is thus evident that taurine has considerable effects upon the nervous system and muscles, effects which could be directly involved in the pathophysiology of Friedreich's disease. Unfortunately the exact mode of action is still not clearly determined, but many of these functions have been involved in producing some of the biochemical changes reported above, as well as many of the symptoms.

In our last overview (Barbeau, 1980), we have demonstrated in detail how an energy production defect in mitochondria could produce the cardiomyopathy and the dying back neuropathy in the dorsal root ganglia large fibers (and all the consequent symptoms of scoliosis, posterior column symptoms, areflexia and ataxia). We thus confirmed the mechanism proposed by Spencer et al (1979) for polyneuropathies. This is illustrated in Fig. 15. These conclusions are not surprising if one recalls that of all the organs, the heart is active every minute of the day, that muscles require considerable energy to produce work and finally that the bipolar large cells of the dorsal pool ganglia have the longest axones in the body! These organs would thus be the prime candidates for damage consecutive to an energy production defect. In a recent important paper, Darsee and Heymsfield (1981) have shown elevated urinary taurine levels in a large kindred with congestive cardiomyopathy. Ten other family members had mitral-valve prolapse and elevated urinary taurine values. One member with mitral valve prolapse died suddenly. Myocardial taurine values were decreased, as were the concentrations in 4 members with congestive cardiomyopathy and myocardial fibrosis.

In the same overview (Barbeau, 1980) and in Fig. 6 of the present paper, I have discussed how changes in mitochondrial membrane composition (particularly in 18:2) or fluidity could produce deficiencies in a series of mitochondrial matrix and inner

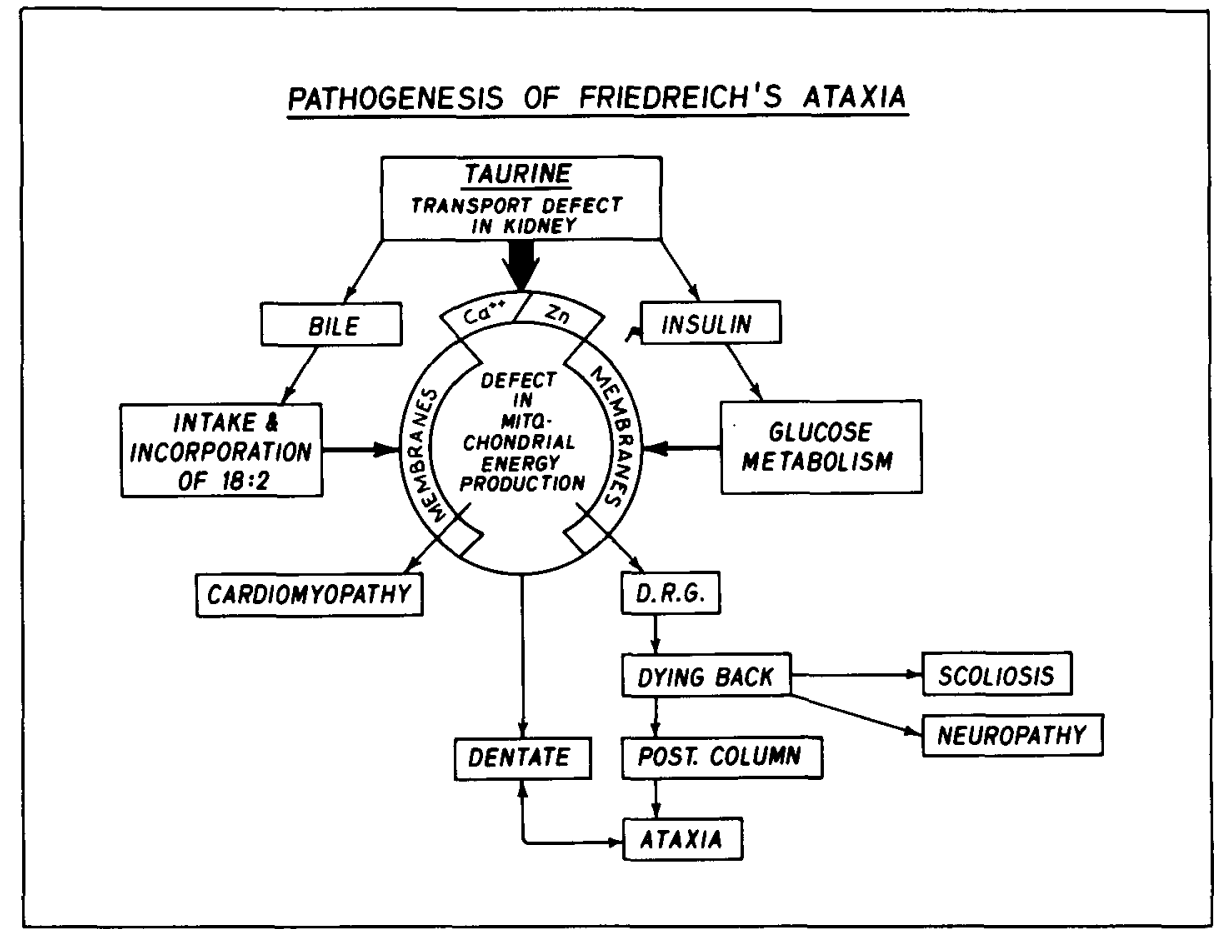

Figure 15 - A scheme to relate the main clinical and biochemical findings in Friedreich's disease to the postulated defect in taurine transport.

membrane enzymes: PDH/LAD, $\alpha$ $\mathrm{KGDH}, \quad \mathrm{VDH}$ and GDH. Such impairment of the availability of substrates (glucose/pyruvate, glutamate, branched chain amino acids) is sufficient to produce an energy deficit and partial uncoupling of the respiratory chain. Stumpf and collaborators (1982) have now added the finding of a new block at the level of mitochondrial malic enzyme. Whether this block is a primary genetic event (their hypothesis), or a down-regulation as a consequence of the other partial blocks reported above (our interpretation), this shut-down of the safety valve further interferes with the free flow of Krebs cycle intermediates.

It is now important to see how a taurine defect could contribute to the mitochondrial membrane abnormality. This could be directly through nonchelation of the zinc moiety which would affect the amino acid membrane transport systems as well as the action of insulin on glucose transport. Another possible mode of action is through the modulation of calcium binding to intra cellular organelles, particularly the endoplasmic reticulum (Pasantes-Morales*, 1982). Finally, a defect affecting the availability of taurine for conjugation in the liver could influence the incorporation of fatty acids (18:2) within bile lecithins, thus the eventual availability of $18: 2$ for incorporation to intestinal chylomicron phospholipids. If the taurine uptake defect postulated for the kidney is also present in the intestinal brush border membrane, uptake of taurine in the entero-portal circulation would be deficient. Since most of the taurine provided to the liver originates either from the diet or from reclaimed intestinal taurine, the end-result would be a net deficit in taurine presented to the liver conjugating mechanism, thereby inducing a compensatory synthesis of the amino acid. The induced correction could be translated into modified $\mathrm{G} / \mathrm{T}$ ratios and therefore an abnormal loss of taurine through the bile, still further amplifying the deficit (see Barbeau, Bouchard et al, 1982, this issue). The secondary effects of these changes in the bile could be important: reduced conjugation to glycine (as shown by reduced formation of hippuric acid from benzoic acid), and possibly interference by the free bile acids with the uptake 
and incorporation of unsaturated fatty acids into bile lecithins (see above).

In summary, I feel that the presence of a transport defect for taurine could be a major contributing factor for all of the symptoms of Friedreich's disease, particularly the primary symptoms previously listed (Table 2): the cardiomyopathy, areflexia and dorsal column signs. The transport defect, which we postulate to affect the high affinity-low capacity transport of taurine (TH system) could be $a$ primary event in Friedreich's disease. Only further studies will tell whether it is the primary event or whether another enzyme deficiency produces this transport impairment.

\section{ACKNOWLEDGEMENTS}

The studies in the author's laboratory were supported by grants from l'Association Canadienne de l'Ataxie de Friedreich, the $O$. Malette Foundation of the Hôtel-Dieu Hospital, La Fondation Yvon Deschamps and the Ministry of National Health and Welfare (Ottawa). The data quoted is the result of studies by a multitude of collaborators who have been the authors of individual articles, but the interpretation and opinions given in this paper are my sole responsibility and do not necessarily reflect the opinions of individual members of the QCSFA. I would like to express my gratitude to Miss D. Bedard and Miss S. Paris for their nursing assistance, to Miss Isabelle Morin for the high quality of her art work in this and previous issues, to Mrs. Hélène L. Crête for having acted as coordinating secretary of Phase III, Part Two and for typing the manuscripts. To all my collaborators, named and unnamed, goes my sincere gratitude for their unfailing faith in this endeavour. Finally, to Claude St-Jean, the driving force behind the QCSFA, the wish that the light now seen at the end of the tunnel will bring hope to him and other sufferers from this terrible disease.

\section{REFERENCES}

BARBEAU, A. (1976). Friedreich's Ataxia 1976 - An overview. Can. J. Neurol. Sci. 3: 389-397.

BARBEAU, A. (1978). Friedreich's Ataxia 1978 - An overview. Can. J. Neurol. Sci. 5: 161-165.

BARBEAU, A. (1979). Friedreich's Ataxia 1979 - An overview. Can. J. Neurol. Sci. 6: 311-319.
BARBEAU, A. (1980). Friedreich's Ataxia 1980 - An overview of the physiopathology. Can. J. Neurol. Sci. 7: 455-468.

BARBEAU, A., CHARBonNEAU, M. and CLOUTIER, T. (1980). Leukocyte glutamate dehydrogenase activity in various hereditary ataxias. Can. J. Neurol. Sci. 7: 421-424.

BARBEAU, A. and DONALDSON, J. (1974). Zinc, taurine and epilepsy. Arch. Neurol. 30: $52-58$.

BARBEAU, A. and HUXTABLE, R.J. (1978). Taurine and Neurological Disorders. Raven Press, New York.

BARBEAU, A., INOUE, N., TSUKADA, Y. and BUTTERWORTH, R.F. (1975). The neuropharmacology of Taurine. Life Sci. 17: 669-677.

BAKER, H. and FRANK, O. (1965). Panothenic acid. in Clinical Vitaminology. Methods and Interpretation. pp. 54-63.

BASSEN, F.A. and KORNZWEIG, A.L. (1950). Malformation of the erythocytes in a case of atypical retinitis pigmentosa. Blood 5: 381-386.

BAYOUMI, R.A. and ROSALKI, S.B. (1976). Evaluation of methods of coenzyme activation of erythrocyte enzymes for detection of deficiency of Vitamins $B_{1}, B_{2}$ and $B_{6}$. Clin. Chem. 22: 327-335.

BRDICZKA, D. and PETTE, D. (1971). Intra and extramitochondrial isozymes of (NADP) malate dehydrogenase. Eur. J. Biochem. 19: 546-551.

BUTTERFIELD, D.A. and MARKESBURY, W.R. (1980). Specificity of biophysical and biochemical alterations in erythrocyte membranes in neurological disorders - Huntington's Disease, Friedreich's ataxia, Alzheimer's Disease, amyotrophic lateral sclerosis, and myotonic and Duchenne muscular dystrophy. J. Neurol. Sci. 47: 261271.

BUTTERWORTH, R.F., HAMEL, E., LANDREVILLE, F. and BARBEAU, A. (1979). Amino acid changes in thiamine-deficient encephalopathy: some implications for the pathogenesis of Friedreich's Ataxia. Can. J. Neurol. Sci. 6: 217-222.

BUTTERWORTH, R.F., SHAPCOTT, D., MELANCON, S., BRETON, G., GEOFFROY, G., LEMIEUX, B. and BARBEAU, A. (1976). Clinical laboratory findings in Friedreich's ataxia. Can. J. Neurol. Sci. 3: 355-359.

CARREAU, J.P., LAPOUS, D. and RAULIN, J. (1977). Signification des acides gras essentiels dans le métabolisme intermédiaire. Hypothèses sur la synthèse de l'acide lipoique. Biochimie 59: 487-496.

COHEN, P.T. and OMENN, G.S. (1972). Human malic enzyme: high frequency polymorphism of the mitochondrial form. Biochem. Genet. 7: 303-311.
CONSTANTOPOULOS, G., CHANG, C.S. and BARRANGER, J.A. (1980). Normal pyruvate dehydrogenase complex activity in patients with Friedreich's ataxia. Ann. Neurol. 8: 636-639.

DARSEE, J.R. and HEYMSFIELD, S.R. (1981). Decreased myocardial taurine levels and hypertaurinuria in a kindred with mitralvalve prolapse and congestive myopathy. New Engl. J. Med. 304: 129-135.

DAVIGNON, J., HUANG, Y.S., WOLF, J.P. and BARBEAU, A. (1979). Fatty acid profile of major lipid classes in plasma lipoproteins of patients with Friedreich's ataxia - Demonstration of a low linoleic acid content most evident in the cholesterol-ester fraction. Can. J. Neurol. Sci. 6: 275-283.

ELIAS, E., MULLER, D.P.R. and SCOTT, J. (1981). Association of spino-cerebellar disorders with cystic fibrosis on chronic childhood cholestasis and very low serum vitamin E. The Lancet 2: 1319-1321.

EVANS, O.B. (1981). Normal muscle pyruvate oxidation in spino-cerebellar degenerations. Ann. Neurol. 9: 93-94.

FILLA, A., BUTTERWORTH, R.F. and BARBEAU, A. (1979). Pilot studies on membranes and some transport mechanisms in Friedreich's ataxia. Can. J. Neurol. Sci. 6: 285-289.

FILLA, A., BUTTERWORTH, R.F., GEOFFROY, G., LEMIEUX, B. and BARBEAU, A. (1978). Platelet taurine uptake in spinocerebellar degeneration. Can. J. Neurol. Sci. 5: 119-123.

FILLA, A., POSTIGLIONE, A., RUBBA, P., PATTI, L., DE MICHELE, G., PALMA. V., BRESCIA MORRA, V. and CAMPANELLA, G. (1980). Plasma lipoprotein concentration and erythrocyte membrane lipids in patients with Friedreich's ataxia. Acta Neurol. NS2: 382-389.

FRENKEL, R. and COBO-FRENKEL, A. (1973). Differential characteristics of the cytosol and mitochondrial isozymes of malic enzyme from bovine brain - Effects of dicarboxylic and sulfhydryl reagents. Archs. Biochem. Biophys. 158: 323-330.

GEOFFROY, G., BARBEAU, A., BRETON, G., LEMIEUX, B., AUBE, M., LEGER, C. and BOUCHARD, J.P. (1976). Clinical description and Roentgenologic evaluation of patients with Friedreich's ataxia. Can. J. Neurol. Sci. 3: 279-386.

GOLDBERG, A.L. and ODESSEY, R. (1972). Oxidation of amino acids by diaphragm from fed and fasted rats. Am. J. Physiol. 223: $1384-1391$.

GOODMAN, H.O., CONNOLY, B.M., McLEAN, W. and RESNICK, M. (1980) Taurine transport in epilepsy. Clin. Chem. 26: 414-419.

GREENFIELD, J.G. (1954). The spinocerebellar degenerations. Black well Scientific Publications. Oxford. 
HENDERSON, N.S. (1966). Isozymes and genetic control of NADP-malate dehydrogenase in mice. Archs. Biochem. Biophys. 117: 28-33.

HUANG, Y.S., CUNNANE, S.C., HORROBIN, D.F. and DAVIGNON, J. (1982) Most biological effects of zinc deficiency corrected by $\gamma$-linolenic acid (18:3w6) but not by linoleic acid $(18: 2 w 6)$. Atherosclerosis 41: 193-207.

HUANG, Y.S., MARCEL, Y.L., VEZINA, C., BARBEAU, A. and DAVIGNON, J. (1980). Lecithin: cholesterol acyltransferase activity and fatty acid composition of erythrocyte phospholipids in Friedreich's ataxia. Can. J. Neurol. Sci. 7: 429-434.

HUANG, Y.S., NESTRUCK, A.C., BARBEAU, A., BOUCHARD, J.P. and DAVIGNON, J. (1978). Plasma lipids and lipoproteins in Friedreich's ataxia and familial spastic ataxia - Evidence for an abnormal composition of high density lipoproteins. Can. J. Neurol. Sci. 5: 149-156.

HUXTABLE, R.J., AZARI, J., REISINE, T., JOHNSON, P., YAMAHURA, H.I. and BARBEAU, A. (1979). Regional distribution of amino acids in Friedreich's ataxia brains. Can. J. Neurol. Sci. 6: 255-258.

HUXTABLE, R.J. and BARBEAU, A. (1976) Editors. Taurine. Raven Press, New York.

HUXTABLE, R.J. and PASANTESMORALES, H. (1982). Editors. Taurine in Nutrition and Neurology. Adv. Exp. Med. Biol. Vol. 139, Plenum Press, N.Y.

JACOBSEN, J.G. and SMITH, L.H. (1968). Biochemistry and physiology of taurine and taurine derivatives. Physiol. Reviews 48: 424-511.

KARK, R.A.P., BLASS, J.P. and ENGEL, W.K. (1974). Pyruvate oxidation in neuromuscular disease - Evidence for a genetic defect in two families with the clinical syndrome of Friedreich's ataxia. Neurology 24: 964-971.

KARK, R.A.P., and RODRIGUEZ-BUDELLI, M.M. (1979). Clinical correlations of partial deficiency of lipoamide dehydrogenase. Neurology 29: 1006-1013.

KARK, R.A.P. and RODRIGUEZ-BUDELLI, M.M. (1979). Pyruvate dehydrogenase deficiency in spino-cerebellar degenerations. Neurology 29: 126-131.

KARK, R.A.P., RODRIGUEZ-BUDELLI, M., PERLMAN, S., GUELLEY, W.F. and TOROK, K. (1980). Preclinical diagnosis and carrier detection in ataxia associated with abnormalities of lipoamide dehydrogenase. Neurology 30: 502-508.

LANDRISCINA, C., MEGLI, F.M. and QUAGLIARIELLO, E. (1976). Turnover of fatty acids in rat liver cardiolipin: comparison with other mitochondrial phospholipids. Lipids 11:61-65.
LAUNAY, M., LAPOUS, D. and RAULIN, J. (1981). Control of replication by dietary lipids and namely by linoleic acid in liver and adipose tissue of developing rats. Prog. Lipid. Res. 20: 331-338.

LEE, S.H. and DAVIS, E.J. (1979). Carboxylation and decarboxylation reactions Anaplerotic flux and removal of citrate cycle intermediates in skeletal muscle. J. Biol. Chem. 254: 420-430.

LEMIEUX, B., BARBEAU, A., BERONIADE, V., SHAPCOTT, D., BRETON, G., GEOFFROY, G. and MELANCON, S. (1976). Amino acid metabolism in Friedreich's ataxia. Can. J. Neurol. Sci. 3: 373-378.

LIN, R.C. and DAVIS, E.J. (1974). Malic enzyme of rabbit heart mitochondria. J. Biol. Chem. 249: 3867-3875.

LIVINGSTONE, I.R., MASTAGLIA, F.L. PENNINGTON, R.J.T. (1980). An investigation of pyruvate metabolism in patients with cerebellar and spino-cerebellar degeneration. J. Neurol. Sci. 48: 123-132.

LOMBARDINI, J.B. (1975). An enzymatic derivative double-isotope assay for measuring tissue levels of taurine. J. Pharmacol. Exp. Ther. 193: 301-308.

LUBOZYNSKI, M.F, and ROELOFS, R.I. (1975). Friedreich's ataxia: a review of recent literature. South. Med. J. 68: 757-763.

MELANCON, S.B., GRIGNON, B., LEDRU, E., GEOFFROY, G., POTIER, M., DALLAIRE, L. and VANASSE, M. (1980). The beta-amino acid transport system in Friedreich's ataxia. Can. J. Neurol. Sci. 7: 441-446.

MORGAN, R.O., NAGLIE, G., HORROBIN, D.F. and BARBEAU, A. (1979). Erythrocyte protoporphyrin levels in patients with Friedreich's and other ataxias. Can. J. Neurol. Sci. 6: 227-232.

PERRY, T.L., HANSEN, S., CURRIER, R.D. and BERRY, K. (1978). Abnormalities in neurotransmitter amino acids in dominantly inherited cerebellar disorders. Adv. Neurol. 21: $303-314$

PURKISS, P., BARAITSER, M., BORUD, $O$. and CHALMERS, R.A. (1981). Biochemical and clinical studies of Friedreich's ataxia. J. Neurol. Neurosurg. Psych. 44: 574-580.

REED, L.J. (1974). Multienzyme complexes. Accounts of chemical Research 7: 40-46.

REFSUM, S. (1946). Heredopathia atactica polyneuritiformis: a familial syndrome not hither to described. A contribution to the clinical study of the hereditary diseases of the nervous system. Acta psychiat. Scand. Suppl. 38: 1-303.

ROBINSON, N. (1968). Chemical changes in spinal cord in Friedreich's ataxia and motor neurone disease. J. Neurol. Neurosurg. Psych. 31: 330-333.
RODRIGUEZ-BUDELLI, $M$. and KARK, R.A.P. (1978). Kinetic evidence for a structural abnormality of lipoamide dehydrogenase in two patients with Friedreich's ataxia. Neurology 28: 12831286.

SAUER, L.A., DAUCHY, R.T. and NAGEL, W.O. (1979). Identification of a NAD(P)+ Dependent 'Malic' enzyme in small intestinal-mucosal mitochondria. Biochem. J. 184: $185-188$.

SIDDIQUIT, U.A., GOLDFLAM, T. and GOODRIDGE, A.G. (1981). Nutritional and hormonal regulation of the translatable levels of malic enzyme and albumin mRNA in avian liver cells in vivo and in culture. $J$. Biol. Chem. 256: 4544-4550.

SIMPSON, E.R. and ESTABROOK, R.W (1969). Mitochondrial malic enzyme: the source of reduced nicotinamide adenine dinucleotide phosphate for steroid hydroxylation in bovine adrenal cortex mitochondria. Archs Biochem. Biophys. 129: 384-395.

SIMPSON, D.M. and POULSON, R. (1977). Effects of lipids on the activity of ferrochelatase. Biochem. Biophys. Acta 482: 461-469.

SPENCER, P.S., SABRI, M.I., SCHAUMBURG, H.H. and MOORE, C.L. (1979). Does a defect of energy metabolism in the nerve fiber underlie axonal degeneration in polyneuropathies? Ann. Neurol. 5: 501-507.

STUMPF, D.A., McCABE, E.R.B., PARKS, J.K., BULLEN, W.W. and SCHIFF, S. (1979). Loosely coupled mitochondrial oxidative phosphorylation induced by protoporphyrin. Biochem. Med. 21: 182-189.

STUMPF, D., PARKS, J., EGUREN, L. and HAAS, R. (1981). Mitochondrial malic enzyme deficiency in Friedreich's ataxia. Ann. Neurol. 10: 283 .

STUMPF, D.A., PARKS, J.K., EGUREN, L.A. and HAAS, R. (1982). Friedreich's ataxia: III - Mitochondrial malic enzyme deficiency. Neurology(Ny) 32: 221-227.

SWIERCZYNSKI, J. (1980). Purification and some properties of extramitochondrial malic enzyme from rat skeletal muscle. Biochem. Biophys. Acta. 616: 10-21.

THOREN, C. (1962). Diabetes mellitus in Friedreich's ataxia. Acta Paediat. 51 (suppl. 135): $239-247$

THURSTON, J.H., HAUHART, R.E. and NACCARATO, E.F. (1981). Taurine: possible role in osmotic regulation of mammalian heart. Science 214: 1373-1374. 
TOLIS, G., MENTA, A., HARVEY, C., ANDERMANN, E., ANDERMANN, F. and BARBEAU, A. (1980). Friedreich's ataxia and glucose tolerance: 1 . the effect of ingested glucose on serum glucose and insulin values in homozygotes, obligate heterozygotes and potential carriers of the Friedreich's ataxia gene. Can. J. Neurol. Sci. 7: $397-400$.
TYRER, J.H. (1975). Friedreich's ataxia. Handbook of clinical neurology. vol. 21: 319-364. P.J. Vinken and G.W. Bruyn, Editors, North-Holland Publishing Co. Amsterdam.

WALKER, J.L., CHAMBERLAIN, $S$. and ROBINSON, N. (1980). Lipids and lipoproteins in Friedreich's ataxia. J. Neurol. Neurosurg. Psychiat. 43: 111-117.
YAO, J.K. and DYCK, P.J. (1978). Lipid abnormalities in hereditary neuropathy. Part 2: serum phospholipids. J. Neurol. Sci. 36. 225 236.

YAO, J.K. and DYCK, P.J. (1979). Accumulation of polyunsaturated fatty acids in developing peripheral nerve. Proc. Amer. Society Neurochem. 12: 214. 